Published in final edited form as:

Nat Immunol. 2008 January ; 9(1): 73-80.

\title{
Suppression of IgE-mediated allergic responses by Rgs13
}

\author{
Geetanjali Bansal ${ }^{1,{ }^{*}}$, Zhihui Xie $^{1,{ }^{*},}$ Sudhir Rao ${ }^{2, \#}$, Karl H. Nocka $^{2,{ }^{* *}, \text { and Kirk M. Druey }}{ }^{1,3}$ \\ 1 Molecular Signal Transduction Section, Laboratory of Allergic Diseases, National Institute of Allergy and \\ Infectious Diseases, NIH, Bethesda, MD 20892
}

2 UCB Pharma, Inc., Cambridge, MA 02139

\section{Abstract}

Mast cells provoke allergic responses through degranulation and release of proinflammatory mediators after antigen crosslinking of the high affinity immunoglobulin E (IgE) receptor (FceRI).

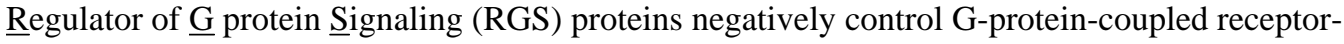
mediated signaling through GTPase accelerating protein (GAP) activity. Here, we show that Rgs 13 inhibits allergic responses by physically interacting with the regulatory p $85 \alpha$ subunit of PI3K in mast cells and disrupting its association with an FceRI-activated scaffold complex. Rgs $13^{-1-}$ mice exhibited increased IgE-mediated mast cell degranulation and anaphylaxis. Thus, apart from its regulation of GPCRs, Rgs13 inhibits immune receptor-induced signalosome assembly in MCs. Abnormal Rgs13 expression or function may underlie some cases of idiopathic anaphylaxis or disorders of amplified MC activity.

MCs lie in close proximity to nerves and blood vessels in organs exposed to constant environmental challenge such as skin and respiratory and gastrointestinal tract mucosae, suggesting a sentinel function in the innate immune response ${ }^{1}$. MCs also provoke allergic diseases such as asthma and anaphylaxis accompanied by high levels of Ag-specific IgE. In allergic individuals, $\mathrm{Ag}$ crosslinks IgE bound to FceRI on MCs, eliciting release of proinflammatory compounds such as histamine and synthesis of leukotrienes and cytokines. Collectively, these mediators initiate type I hypersensitivity reactions characterized by increased vascular permeability, edema, and smooth muscle contraction.

Fc\&RI is a multiunit immune recognition receptor consisting of $\alpha, \beta$, and two $\gamma$ chains. The $\alpha$ subunit binds IgE while the $\beta$ and $\gamma$ subunits transduce extracellular signals ${ }^{2}$. FceRI crosslinking by IgE/Ag induces phosphorylation of immunoreceptor-based tyrosine activation motifs (ITAMs) in the intracellular portion of the $\beta$ and $\gamma$ chains by Lyn tyrosine kinase, which attracts Syk kinase to the $\gamma$ chain. Tyrosine phosphorylation of Syk then propagates the signaling pathway by recruitment and activation of $\mathrm{PI}(3) \mathrm{K}$, phospholipase $\mathrm{C} \gamma(\mathrm{PLC} \gamma)$, and mitogen-activated protein kinase (MAPK). PI(3)K has an essential function in MC homeostasis and allergic responses ${ }^{3}$. Deletion of $\mathrm{p} 110 \delta$, the principal catalytic PI(3)K subunit in BMMCs, significantly impairs Ag-induced degranulation ${ }^{4}$. PI(3)K-mediated activation of PLC $\gamma$, which catalyzes formation of inositol-1, 4, 5 trisphosphate (IP3), evokes a rise in intracellular $\mathrm{Ca}^{++}$ concentration leading to degranulation 5 .

Although allergic reactions have been attributed mainly to IgE-mediated MC activation, GPCRs may amplify IgE-mediated responses ${ }^{5}$. Stimulation of adenosine $\left(\mathrm{A}_{3}\right)$, chemokine, or prostaglandin (EP3) receptors accentuates MC degranulation induced by $\mathrm{Ag}^{6-9}$. In contrast

3 To whom correspondence should be addressed: kdruey@niaid.nih.gov.

* These authors contributed equally to this work.

\#Present address: Merck Research Laboratories, Boston, MA 02115

*** Present address: Wyeth Research, Respiratory Diseases Division Cambridge, MA 02140. 
to FceRI, GPCRs catalyze GDP-GTP exchange on the $\alpha$ subunit of a heterotrimeric G protein to activate a variety of effector pathways ${ }^{10}$. Signaling terminates through the intrinsic GTPase activity of the $\alpha$ subunit, which results in conversion of $\mathrm{G} \alpha-\mathrm{GTP}$ to G $\alpha$-GDP. G $\alpha-\mathrm{GDP}$ binds $\mathrm{G} \beta \gamma$ with high affinity, re-constituting the inactive heterotrimer.

RGS proteins specify GPCR signaling durability and intensity through GTPase accelerating (GAP) activity on $\mathrm{G} \alpha$ subunits and/or antagonism of $\mathrm{G} \alpha$-effector interactions, which results in desensitization to continuous ligand exposure ${ }^{11}$. The RGS protein family comprises more than 25 members in mammalian cells which contain a 120 amino acid RGS domain mediating direct binding to heterotrimeric G protein $\alpha$ subunits, GAP activity, and inhibition of G-proteinmediated signaling ${ }^{12}$. RGS isoforms can be further divided into subfamilies on the basis of additional protein interaction motifs. However, the R4 subfamily of RGSs (RGS1-5, 8, 13, 16, 18, and 21) contains only short peptide sequences flanking the RGS domain. Despite extensive characterization of their biochemical actions in vitro, the physiological function of most R4 RGS proteins remains unknown.

Here, we investigated R4 RGS proteins as potential regulators of allergic inflammation. We identified an unexpected function for Rgs13 as a negative regulator of IgE-mediated MC degranulation and anaphylaxis which does not involve its GAP activity. Rgs13 suppressed Aginduced $\mathrm{MC}$ activation by binding $\mathrm{PI}(3) \mathrm{K}$ and inhibiting protein-protein interactions within the FceRI signaling pathway.

\section{RESULTS}

\section{Enrichment of Rgs13 in MCs}

Polymerase chain reaction (PCR) and microarray analysis of various sources of MC RNA for R4 RGS family members revealed expression of $\operatorname{Rgs} 1,8,13,16^{13}$ and 18 (data not shown). We focused on Rgs13 because microarray studies of purified human cell subsets showed restricted RGS13 expression in MCs compared to other hematopoietic cells (Fig. 1a). We also detected Rgs13 in mouse bone marrow-derived MCs (BMMCs) by immunofluorescent staining (Fig. 1b). To study the function of Rgs13 in MCs, we generated Rgs 13-/- mice. We replaced exon 4 of $R g s 13$ with an in-frame $L a c Z$ cassette to employ $\beta$-galactosidase activity as a surrogate for physiological Rgs13 expression (Supplementary Fig. 1 online). $\beta$ galactosidase analysis of Rgs13-/- mice confirmed Rgs13 expression in BMMCs and Toluidine blue ${ }^{+}$MCs in several organs including skin, lung, and conjunctiva (Supplementary Fig. 2 online and data not shown).

RGS expression may change rapidly in response to numerous stimuli including GPCR ligands, and in some instances impart feedback control 11,14 . To delineate Rgs 13 expression patterns that might correlate with regulation of specific $\mathrm{MC}$ receptors, we stimulated BMMCs with various compounds and measured Rgs 13 levels by quantitative real-time PCR. Whereas adenosine, C5a, and stem cell factor (SCF) had modest or no effects on Rgs 13 expression, eotaxin treatment decreased $\mathrm{Rgs} 13$ levels by nearly 50\% (Fig. 1c and data not shown). In contrast, Ag stimulation of BMMCs was accompanied by a 4-5 fold increase in Rgs 13 mRNA levels after 24h (Fig. 1c). Prolonged Ag treatment of IgE-sensitized BMMCs also increased Rgs13 protein levels (Fig. 1d). Thus, Ag-evoked upregulation of Rgs13 raised the possibility that this RGS protein may have a function in IgE-mediated MC responses.

\section{Increased MC degranulation in the absence of Rgs13}

Rgs13 deficiency did not significantly impact maturation or morphology of cultured BMMCs, nor did it affect surface receptor expression of FceRI (Supplementary Figs. 2-3 online). To determine whether Rgs13 regulated MC activation, we examined degranulation of MCs from 
WT and Rgs 13-/- mice. Surprisingly, Ag-evoked degranulation by Rgs13-deficient BMMCs was significantly greater over a range of Ag concentrations (Fig. 2a). In response to the optimal Ag concentration, Rgs 13-/- MCs released nearly twice the amount of $\beta$-hexosaminidase as did WT counterparts. Response to $\mathrm{Ca}^{++}$ionophore was similar in WT and Rgs13-/- MCs, excluding a generalized abnormality of exocytosis (Fig. 2b).

Potentiation of Ag-mediated degranulation may occur by autocrine secretion of GPCR ligands such as adenosine, resulting in activation of a Gai-coupled signaling pathway 15 . To evaluate whether Rgs13 GAP activity toward Gai and inhibition of GPCR-mediated signaling contributed to its effect on Ag-induced degranulation, we pre-incubated cells with pertussis toxin (PTX) prior to Ag stimulation. PTX selectively inactivates members of the Gai/o family of $\mathrm{G}$ proteins ${ }^{10}$. PTX did not significantly affect Ag-induced degranulation of BMMCs (Fig. 2c). In addition, Ag-evoked degranulation of Rgs 13-I- BMMCs remained significantly higher than WT in the presence of PTX (Fig. 2c). This finding implies that the increased response to $\mathrm{Ag}$ seen in Rgs13-deficient BMMCs does not involve Gai. Further, reconstitution of Rgs 13-I - BMMCs with recombinant TAT fusion proteins of either WT RGS13 or RGS13 (EN59/60AA), which contains a mutation that eliminates RGS-G $\alpha$ binding and GAP activity ${ }^{16}$, significantly inhibited $\mathrm{IgE} / \mathrm{Ag}$ induced degranulation (Fig. 2d). These results indicated that the enhanced degranulation of Rgs 13-/- BMMCs was due to the absence of Rgs13 and that Rgs13 inhibited IgE-mediated MC degranulation independent of its GAP activity.

\section{Increased anaphylactic responses of $\boldsymbol{R g s 1 3 - / - ~ m i c e ~}$}

To evaluate MC degranulation in situ, we compared passive cutaneous anaphylaxis (PCA) in WT and Rgs 13-1- mice. PCA was increased almost two-fold in Rgs 13-1- mice, judged by visual inspection of the skin (Fig. 3a) and spectrophotometric quantitation of Evans blue dye extracted from the reaction site (Fig. 3b). Similarly, passive systemic anaphylaxis was enhanced in several organs of Rgs 13-l- mice (Supplementary Fig. 4 online). MC counts and morphology in several organs including skin were similar in Rgs 13-/- and WT mice (Table 1 and Supplementary Fig. 2 online), Thus, the enhanced anaphylaxis observed in Rgs 13-/- mice was likely due to increased $\mathrm{MC}$ degranulation rather than increased tissue MC numbers.

\section{Rgs13 interacts with $\mathrm{PI}(3)$ kinase}

Collectively, these results indicated that Rgs 13 might directly affect the FceRI signaling route leading to MC degranulation. Given that tyrosine phosphorylation events are critical for Agevoked MC activation, we searched for Rgs13-interacting proteins potentially responsible for its regulation of Ag-mediated signaling by incubating BMMC lysates with GST-RGS13 and immunoblotting pulldown reactions with anti-phosphotyrosine. GST-RGS13 extracted a tyrosine-phosphorylated protein doublet of $\sim 80-85 \mathrm{kDa}$ (Fig. 4a). Further analysis revealed that one of these RGS13-associated proteins was the p85 $\alpha$ regulatory subunit of $\mathrm{PI}(3) \mathrm{K}$. We also observed interaction of $\mathrm{p} 85 \alpha$ with Rgs13 in rat basophilic leukemia (RBL-2H3) cells, a MC line with higher levels of endogenous Rgs13 than BMMCs (Fig. 4b).

FceRI stimulation activates Class IA PI(3)Ks consisting of dimers of $\mathrm{p} 85 \alpha$ or $\beta$ and either $\mathrm{p} 110 \alpha, \beta$, and $\delta$ catalytic subunits ${ }^{17}$. Tyrosine phosphorylation of the adaptor protein Grb2 associated binder 2 (Gab2) recruits $\mathrm{p} 85$ to the IgE receptor complex through a Src homology 2 (SH2) domain in $\mathrm{p}^{8} 5^{18-20}$. Using recombinant proteins, we found that RGS13 directly bound p85a (Fig. 4c). Although the Src family kinases such as Lyn may phosphorylate tyrosine residues on $\mathrm{p} 85 \alpha$, the exact function of $\mathrm{p} 85 \alpha$ tyrosine phosphorylation remains unclear ${ }^{21}$, 22. In this cell-free system, p85a tyrosine phosphorylation appeared to be necessary for RGS13 complexation as no RGS13 binding to $p 85 \alpha$ was observed in the absence of $p 85 \alpha$ phosphorylation (Supplementary Figure 5 online). In contrast, RGS13 was not phosphorylated, 
suggesting that only p85 $\alpha$ phosphorylation was required for RGS13-p85 $\alpha$ complex formation. In addition, immunoprecipitation of endogenous p85 from Ag-stimulated BMMC lysates extracted Rgs13 (Fig. 4d). p85 $\alpha$ phosphorylation has been described in both unstimulated RBL mast cells and BMMCs, which may account for constitutive PI3K activity observed in these cells 23,24 . Although we detected Rgs 13 interaction with p85a in unstimulated cells, this finding probably reflects basal phosphorylation of p85a. Collectively, our results suggest that Ag stimulation increases Rgs13-p85 $\alpha$ association. Finally, Rgs13 did not affect Ag-induced p85 $\alpha$ phosphorylation, as evidenced by the similar levels of p $85 \alpha$ phosphorylation in WT and Rgs 13-I- BMMCs (Supplementary Figure 6 online).

\section{Rgs13 inhibits Ag-induced $\mathrm{PI}(3) \mathrm{K}$ activation in MCs}

We next asked whether Rgs13 binding to p85 regulated PI(3)K activity in MCs. Consistent with the increased degranulation of Rgs 13-/- BMMCs, Ag-evoked PtdIns(3,4,5)P3 [PIP3] production (Fig. 5a) and Akt phosphorylation (Fig. 5b) were significantly elevated in these cells. Accordingly, events downstream of PI(3)K directly leading to degranulation such as PLC $\gamma 1$ activation (Fig. 5c) and intracellular $\mathrm{Ca}^{++}$mobilization (Fig. 5d) were also increased in the absence of Rgs13. By contrast, Syk phosphorylation, one of the earliest events after receptor activation essential for Ag-induced MC degranulation 25 , was unchanged in Rgs 13-I - BMMCs, indicating that Rgs13 functions downstream of receptor-dependent phosphorylation (Supplementary Fig. 7 online). Erk activation was also unaltered in Rgs 13-I - BMMCs (Supplementary Fig. 7 online). Consistent with the importance of MAP kinases for cytokine synthesis in $\mathrm{MCs}^{5,26}$, Ag-stimulated cytokine production was similar in WT and Rgs13-/- BMMCs (Supplementary Fig. 8 online).

In contrast to the enhanced FceRI-evoked $\mathrm{Ca}^{++}$flux and PI3K activity associated with Rgs13deficiency, overexpression of RGS13 in WT BMMCs by TAT-mediated transduction, which lead to a greater than 2-fold increase in Rgs 13 expression relative to cells transduced with TAT$\beta$-galactosidase (Fig. 6a), inhibited Ag-induced $\mathrm{Ca}^{++}$flux (Fig. 6b) and Akt phosphorylation (Fig. 6c). Thus, Rgs13 levels significantly affect Ag-evoked PI(3)K activity and degranulation of MCs.

\section{Mechanism of $\mathrm{PI}(3) \mathrm{K}$ inhibition by Rgs13}

To define the molecular mechanism whereby RGS proteins regulate PI(3)K activity, we first determined the region in RGS13 mediating binding to $\mathrm{p} 85 \alpha$. This interaction required only the amino-terminal 51 amino acids of RGS13, as GFP-RGS13(1-51) co-immunoprecipitated with mycGFP-tagged p85a in HEK293T cells (Fig. 7a). A TAT-fusion protein comprising RGS13 (1-51) inhibited IgE/Ag-induced MC degranulation comparably to WT RGS13 (Fig. 7b). These studies indicated that the amino-terminus of RGS13 mediates both interaction with the p $85 \alpha$ regulatory subunit of $\mathrm{PI}(3) \mathrm{K}$ in $\mathrm{MCs}$ and the inhibition of $\mathrm{Ag}$-induced degranulation.

To further define how the RGS-p85 $\alpha$ interaction affects PI(3)K function, we examined p85 $\alpha$ protein-protein interactions upon Fc\&RI activation. Ag cross-linking of the IgE receptor activates PI(3)K by recruiting tyrosine kinases such as Syk ${ }^{18}$. Phosphorylation of Gab2 by Syk recruits PI(3)K to a signaling scaffold that includes Grb2 and Gab2 ${ }^{19,20}$. To evaluate p85 $\alpha$ binding to the phosphoGab2-containing complex, we first immunoprecipitated $\mathrm{p} 85 \alpha$ from WT BMMCs transduced with TAT fusion proteins. Anti-p85 $\alpha$ co-immunoprecipitated Gab2 in BMMCs transduced with TAT- $\beta$-galactosidase, while transduction of cells with TATRGS13 resulted in significantly decreased p85-Gab2 complexation compared to control (Fig 7c). Similarly, amounts of p85a co-immunoprecipitated with Gab2 were decreased in Agstimulated WT BMMCs transduced with TAT-RGS13 compared to cells transduced with TAT$\beta$-galactosidase (Fig. 7d). 
This analysis suggested that one mechanism whereby Rgs 13 regulates PI(3)K activity in MCs might involve limiting the association of p85 with the FceRI-associated signaling complex, i.e., by acting as a "reverse" scaffolding protein. If this hypothesis were true, the amount of p85 $\alpha$ associated with Gab2 should be substantially higher in Rgs13-deficient MCs. To assess this possibility, we employed GST-Grb2 beads, which were more efficient in extracting Gab2p85 complexes from BMMCs than immunoprecipitation of either protein. The amount of p85 $\alpha$ associated with GST-Grb2 was substantially higher in Rgs 13-/- BMMCs compared to WT (Fig. 7e). Expression of p $85 \alpha$ and p1 $10 \delta$ as well as expression and phosphorylation of Gab2 were all unchanged in the absence of Rgs13 (Fig. 7e). Collectively, these results suggested that Rgs13 affects p85 $\alpha$ binding to an FceRI-associated signaling complex containing Gab2 and Grb2, which could contribute to the increased PI(3)K activity observed in Rgs 13-I- MCs.

\section{DISCUSSION}

We have uncovered a novel function for the G protein GAP Rgs13 in allergic responses. The physiological importance of Rgs 13 as negative regulator of IgE-mediated MC reactivity was suggested by the markedly enhanced degranulation of Rgs13-deficient MCs and anaphylaxis of Rgs 13-/- mice in response to Ag. Rgs13 appeared to regulate MC degranulation by physically interacting with the p85a subunit of $\mathrm{PI}(3) \mathrm{K}$ and impairing Ag-induced PI(3)K activation.

Several lines of evidence indicate that Rgs13 directly inhibited PI(3)K signaling in MCs independent of its GAP activity. Rgs 13 bound $\mathrm{p} 85 \alpha$ directly, and the interaction required only the Rgs13 amino-terminus (1-51), which does not possess GAP activity (Xie et al. MS submitted). Amplification of MC degranulation by GPCR agonists such as adenosine occurs through activation of the PI(3)K $\gamma$ isoform by G $\beta \gamma$ released from Gai-GTP ${ }^{15}$. PI(3)K $\gamma$ does not associate with p85 subunits 27 , suggesting that Rgs13 would not be expected to regulate PI(3) $\mathrm{K} \gamma$ directly. In our study, inactivation of Gai proteins by PTX did not significantly reduce Agevoked BMMC degranulation, nor did it diminish the differential response of WT and Rgs 13 -/- BMMCs to Ag. Lastly, a mutant RGS13 protein devoid of GAP activity inhibited Agevoked degranulation similar to WT RGS13 (Fig. 2d).

Whereas Ag-evoked degranulation was strongly increased in Rgs 13-1- BMMCs, cytokine production by MCs did not appear to be affected by the loss of Rgs13. Ag-induced cytokine synthesis is controlled by calcium-NFAT and NFkB pathways in addition to MAPKs. Although Ag-elicited PLC $\gamma$ phosphorylation and $\mathrm{Ca}^{++}$release were increased in the absence of Rgs13, MAPK/Erk activation was not affected by Rgs13 deficiency. Preliminary evidence also suggests that neither Jun kinase (JNK) phosphorylation nor NFKB activation were significantly different in WT or Rgs 13-/- BMMCs stimulated with Ag (data not shown). MAPKs are regulated by intracellular $\mathrm{Ca}^{++}$concentration, through activation of PLC $\gamma$ and diacylglycerol (DAG), which in turn activate protein kinase C (PKC). Importantly, however, there are at least four isoforms of PKC identified in MCs that may both positively (PKC $\beta 28)$ and negatively (PKC829) regulate MAPK activity. MAPKs can be also be activated by PKC (and therefore $\mathrm{Ca}^{++}$)-independent pathways ${ }^{30}$.

For these reasons, enhanced Ag-evoked PLC $\gamma$ activity and the resultant increase in $\mathrm{Ca}^{++}$ mobilization in Rgs 13-/- BMMCs could lead to increased degranulation without significantly affecting MAPK activation and cytokine synthesis. Dissociation of cytokine production and degranulation in MCs has been observed in diacylglycerol kinase (DGK) $\zeta$-deficient BMMCs $^{31}$. $\beta$-hexosaminidase release was reduced by $\sim 50 \%$ in DGK $\zeta-/-$ BMMCs. In contrast, the production of IL-6 was enhanced in response to Ag stimulation. In these cells, decreased $\mathrm{Ag}$-evoked $\mathrm{Ca}^{++}$mobilization resulting in reduced PKC $\beta I I$ membrane recruitment 
may have accounted for the suppressed degranulation, while enhanced MAPK/ERK and Akt activation might explain the increased IL-6 production.

In addition to MAPKs, Akt is also a critical mediator of Ag-induced cytokine production ${ }^{32}$. $\mathrm{Ca}^{++} /$calmodulin was recently shown to interact with the pleckstrin homology $(\mathrm{PH})$ domain of $\mathrm{Akt}$, which competes with PIP3 for binding to $\mathrm{Akt}^{33}$. Calmodulin inhibits membrane recruitment of Akt and impairs its subsequent activation. Several members of R4 subfamily of RGS proteins have been shown to interact with calmodulin through a conserved motif in the RGS domain 34,35 . Since Rgs13 contains this sequence, the absence of Rgs13 in BMMCs could result in increased amounts of calmodulin available to inhibit Akt, thus counterbalancing the increased PI3K catalytic activity. Collectively, these results suggested that Rgs 13 might be more important in regulating type I immediate hypersensitivity reactions rather than innate immune functions of MCs involving cytokine synthesis and release.

It is believed that while cytosolic p85/p110 complexes are catalytically inactive, recruitment of SH2 domains in p85 subunits to phosphotyrosine residues in receptors or adaptor proteins activates $\mathrm{PI}(3) \mathrm{K}$ by positioning the p110 subunit in proximity to membrane lipid substrates $^{27}$. Notably, deletion of the p85 $\alpha$ isoform resulted in only minor defects in IgEmediated degranulation of BMMCs while Rgs13-deficiency profoundly affected degranulation and anaphylaxis. We attribute this discrepancy to the fact that the $\mathrm{p} 85 \beta$ isoform, whose expression is clearly upregulated in $\mathrm{p} 85 \alpha$ knockout $\mathrm{MCs}^{36}$, may compensate for the loss of p85 $\alpha$ in these cells. In contrast, Rgs 13 may bind more than one p85 isoform. The increased amount of p85a bound to Gab2 in Rgs 13-/- MCs suggests that Rgs13 inhibits PI(3)K activity by restricting accessibility of $\mathrm{p} 85$ to its FceRI-associated scaffold complex after receptor stimulation, resulting in diminished Ag-induced MC degranulation (Fig. 8).

Rgs 13 binding to $\mathrm{p} 85 \alpha$ and inhibition of PI(3)K signaling required only the 51 amino-terminal amino acids of Rgs13. Recent studies have suggested the amino-terminus of R4 RGS proteins, which adopts an $\alpha$-helical conformation in vivo ${ }^{37}$ but is disordered in the crystal structure of recombinant RGS4 complexed with Gai $1^{38}$ may collaborate with diverse signaling molecules to integrate pathways elicited by various cell surface receptors ${ }^{39}$. Such interactions have been proposed to stabilize the amino-terminus of RGS proteins in distinct conformations depending on the binding partner ${ }^{39}$. For example, some RGSs may selectively regulate a subset of GPCRs by binding additional proteins such as spinophilin 40,41 or the third intracellular loop of the receptor itself ${ }^{42}$.

Rgs13 was previously shown to be expressed primarily in human and murine B lymphocytes. Our microarray analysis of human cells and $\beta$-galactosidase staining of $L a c Z$ knock-in mice indicated that Rgs13 indeed displays very limited tissue expression restricted to lymphocytes, MCs, and endocrine cells of the thymus, GI, and respiratory tracts. Thus, the increased allergic responses of Rgs 13-I- mice were not likely to due enhanced vascular permeability induced by MC vasoactive mediators on end-organ targets. This explanation could account for the observed phenotype if, for example, Rgs 13 were highly expressed in endothelial cells and loss of Rgs13 expression in these cells enhanced signaling to GPCR ligands such as histamine. We did detect binding of other R4 RGSs including RGS1, 4, 5, and 16 to p85 $\alpha$, suggesting that this interaction was common to this subfamily of RGS proteins (data not shown). Since Rgs1 and Rgs13 are abundant in B cells 43,44 and Rgs16 is enriched in activated T cells 45 , 46, RGS proteins may regulate $\mathrm{PI}(3) \mathrm{K}$ activation evoked by $\mathrm{Ag}$ receptors in lymphocytes, which could significantly impact other adaptive immune responses.

In B lymphocytes, Rgs 13 is induced by anti-CD40 and IL-4 stimulation 44 . Here, we showed that Rgs 13 expression in MCs is strikingly upregulated by Ag stimulation. RGS13 expression was recently found to be increased in human basophils treated with $\mathrm{IgE} / \mathrm{Ag}^{47}$. Thus, Ag- 
induced expression of Rgs 13 could potentially restrict or prevent tissue damage from continual MC degranulation due to recurring Ag exposure, which may occur in beekeepers or in patients undergoing immunotherapy. Conversely, loss of RGS function due to reduced expression or inactivating mutation(s) could underlie or contribute to the pathogenesis of disorders characterized by increased MC degranulation, such as idiopathic anaphylaxis.

In summary, we have elucidated a new link between GPCR signaling pathways and the predominantly tyrosine kinase-dependent signaling elicited by immune receptor activation in MCs. Rgs13 regulation of PI(3)K activity resulted in increased MC degranulation and allergic responses. Given the ubiquity of RGS proteins, the evidence presented here for the direct mitigation of PI(3)K signaling by an R4 RGS family member portends a novel and common mechanism by which cells may integrate or specify diverse and/or conflicting extracellular cues. Since PI(3)K also has a critical function in cancer progression and glucose metabolism, further investigation into RGS regulation of $\mathrm{PI}(3) \mathrm{K}$ signaling in these and other systems is warranted in light of this study.

\section{METHODS}

Rgs13-/- mice

We generated Rgs 13-I- mice by targeting exon 4 and replacing it with an in-frame LacZ cassette. Age-matched (4-10 weeks) littermates were used for all experiments. (See Supplementary Information for details on targeting strategy and further characterization of the mice).

\section{Microarray analysis}

We derived human MCs in adult peripheral blood from $\mathrm{CD} 34^{+}$progenitor cells isolated by magnetic bead selection (Miltenyi Biotech) after 6-8 week culture in medium containing 30\% FBS (Hyclone), SCF and GM-CSF (100 $\mathrm{ng} \mathrm{ml}^{-1}$ and $10 \mathrm{pg} \mathrm{ml}^{-1}$, respectively, R \& D Systems) and $2-4 \%$ of a 20 fold concentrate of conditioned medium derived from the immortalized MCM B cell line. Peripheral blood eosinophils were isolated by negative selection of a granulocyte fraction following density gradient separation on Ficoll. RNA was isolated from seven donors and then pooled to run the single sample. $10 \mu \mathrm{g}$ of fragmented target cRNA prepared from total RNA was applied to human U95 GeneChip ${ }^{\circledR}$ microarray chips (Affymetrix ${ }^{\circledR}$ ) per the manufacturer's instructions. Chips were scanned under a low photomultiplier tube setting using the Affymetrix Genechip Fluidics Workstation and average values generated using Affymetrix MAS4.0 software. Expression values from the remainder of the cell subsets were obtained from the Gene Logic, Inc. Bioexpress тм database.

\section{Immunohistochemistry and immunofluorescence}

BMMCs were spread onto glass coverslips by cytospin and stained with polyclonal anti$\mathrm{RGS13}^{44}$ and Texas Red-conjugated anti-rabbit IgG (Vector Labs). Acid Toluidine blue counterstaining was used to locate tissue MCs, and 4'-6-diamidino-2-phenylindole (DAPI, Sigma) staining identified nuclei.

\section{Quantitative Rgs13 expression}

We employed real-time quantitative PCR (qPCR) to evaluate Rgs 13 mRNA in BMMCs stimulated with various agonists using the Platinum SybrGreen qPCR Supermix-Uracil DNA glycosylase mix per the manufacturer's instructions (Invitrogen). Primers used-Rgs 13: GAAAATTGCTTCACGAAGGGG and GCATGTTTGAGTGGGTTCACGAATG GAPDH: AACGACCCCTTCATTGAC and TCCACGACATACTCAGCAC. Rgs 13 values were normalized to GAPDH values. Eotaxin was purchased from Peprotech. 


\section{Mouse mast cell cultures}

All in vitro studies used BMMCs extracted from femurs and cultured for 4-10 weeks in RPMI $+10 \%$ FBS (Gibco) and IL-3 (30 ng ml ${ }^{-1}$, Peprotech). FACS analysis for FceRI was performed at 4 weeks using anti-dinitrophenyl (DNP)-IgE (clone SPE-7, Sigma) and monoclonal fluorescein isothiocyanate-conjugated mouse anti-IgE (BD Biosciences) (routinely $>95 \%{ }^{+}$).

\section{Degranulation and calcium measurement}

We measured release of $\beta$-hexosaminidase as previously described ${ }^{48}$. Briefly, cells were grown overnight in the absence of IL-3 with anti-DNP IgE $\left(100 \mathrm{ng} \mathrm{ml}^{-1}\right)$ for $12 \mathrm{hrs}$. prior to washing in Tyrode's buffer and stimulation with DNP-human serum albumin (HSA, Sigma). Intracellular $\mathrm{Ca}^{++}$concentration was measured in a 96 well plate in triplicate using FLIPR Calcium 3 assay kit and the FLEXStation II automated fluorimeter (Molecular Devices). PTX was purchased from Sigma.

\section{Passive cutaneous and systemic anaphylaxis}

We measured anaphylactic responses as described elsewhere 48,49 .

\section{Biochemical studies}

We performed BMMC stimulation, immunoblotting, GST-pulldowns, and immunoprecipitation essentially as previously described ${ }^{18}$. GST-Grb2 coupled to glutathione sepharose was obtained from Upstate Biotechnology, and GST-RGS13 was expressed in bacteria and purified on glutathione sepharose as per the manufacturer's instructions (GE Biosciences). Antibodies used were purchased as follows: p-Tyr (4G10, Chemicon); GFP, HA,

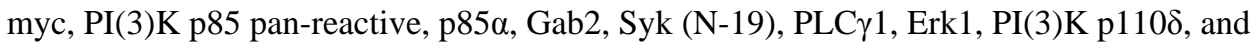
RGS13 (G-12) (Santa Cruz); p-PLC ${ }_{\gamma 1}$ (Biosource), p-Erk1/2, p-Akt(Thr308), Akt (Cell Signaling), chicken anti-RGS13 (ProSci). Plasmids encoding GFP-RGS13 truncation mutants were constructed from pEGFP-RGS13 by PCR. Plasmids encoding mycGFP-PI(3)Kp85 $\alpha$ and HisPI(3)Kp110 $\alpha$, (the gift of J. Silvio Gutkind, National Institute of Dental and Craniofacial Research, National Institutes of Health) were co-transfected into 293T cells together with GFPRGS13 constructs using Lipofectamine 2000 (Invitrogen). We processed cells in buffer containing $20 \mathrm{mM}$ Tris $\mathrm{pH} 7.5,300 \mathrm{mM} \mathrm{NaCl}, 10 \mathrm{mM} \beta$-ME, $10 \%$ glycerol, $1 \%$ Triton X-100, and a protease/phosphatase inhibitor mix (Roche) followed by immunoprecipitation with antimyc. PtdIns $(3,4,5) 3$ levels were determined by thin layer chromatography as described elsewhere 50 and quantified using Storm 860 PhosphorImager and ImageQuant software (Molecular Dynamics).

\section{BMMC transduction with TAT fusion proteins}

Full-length, untagged RGS13, GFP-RGS13, and GFP-RGS13(1-51) were subcloned in-frame into pTAT- ${ }_{6} \mathrm{HA}$ (the kind gift of Stephen Dowdy, University of California, San Diego School of Medicine, who also provided the TAT- $\beta$-galactosidase construct). Recombinant TAT proteins were expressed in Escherichia coli and purified by nickel affinity chromatography essentially as described ${ }^{51}$. Point mutagenesis was performed using the QuikChange kit (Stratagene). TAT fusion proteins were added directly to BMMC cultures 30 min. prior to $\mathrm{Ag}$ stimulation.

\section{Cytokine measurement}

Cytokines in BMMC supernatants were analyzed 24 hrs. after Ag stimulation using the Multiplex Luminex kit according to the manufacturer's instructions (Biosource). 


\section{Supplementary Material}

Refer to Web version on PubMed Central for supplementary material.

\section{Acknowledgements}

We thank Alasdair Gilfillan, Shoko Iwaki, and Silvio Gutkind for numerous reagents and protocols, helpful discussions, and critical review of the manuscript, Gene Logic, Inc. for providing microarray expression data, and Dean Metcalfe for his support.

\section{References}

1. Metz M, Maurer M. Mast cells - key effector cells in immune responses. Trends Immunol. 2007

2. Ra C, Jouvin MH, Kinet JP. Complete structure of the mouse mast cell receptor for IgE (Fc epsilon $\mathrm{RI}$ ) and surface expression of chimeric receptors (rat-mouse-human) on transfected cells. J Biol Chem 1989;264:15323-7. [PubMed: 2527850]

3. Fukao T, et al. Selective loss of gastrointestinal mast cells and impaired immunity in PI3K-deficient mice. Nat Immunol 2002;3:295-304. [PubMed: 11850627]

4. Ali K, et al. Essential role for the p110delta phosphoinositide 3-kinase in the allergic response. Nature 2004;431:1007-11. [PubMed: 15496927]

5. Gilfillan AM, Tkaczyk C. Integrated signalling pathways for mast-cell activation. Nat Rev Immunol 2006;6:218-30. [PubMed: 16470226]

6. Nguyen M, et al. Receptors and signaling mechanisms required for prostaglandin E2-mediated regulation of mast cell degranulation and IL-6 production. J Immunol 2002;169:4586-93. [PubMed: 12370397]

7. Zhong $\mathrm{H}$, et al. Activation of murine lung mast cells by the adenosine A3 receptor. $\mathrm{J}$ Immunol 2003;171:338-45. [PubMed: 12817016]

8. Olivera A, Rivera J. Sphingolipids and the balancing of immune cell function: lessons from the mast cell. J Immunol 2005;174:1153-8. [PubMed: 15661867]

9. Jolly PS, et al. Transactivation of sphingosine-1-phosphate receptors by FcepsilonRI triggering is required for normal mast cell degranulation and chemotaxis. J Exp Med 2004;199:959-70. [PubMed: 15067032]

10. Gilman AG. G proteins: transducers of receptor-generated signals. Annu Rev Biochem 1987;56:61549. [PubMed: 3113327]

11. Willars GB. Mammalian RGS proteins: multifunctional regulators of cellular signalling. Semin Cell Dev Biol 2006;17:363-76. [PubMed: 16687250]

12. Druey KM. Bridging with GAPs: receptor communication through RGS proteins. Sci STKE 2001 2001:RE14.

13. Hernandez-Hansen V, et al. Increased expression of genes linked to FcepsilonRI Signaling and to cytokine and chemokine production in Lyn-deficient mast cells. J Immunol 2005;175:7880-8. [PubMed: 16339523]

14. Taymans JM, Leysen JE, Langlois X. Striatal gene expression of RGS2 and RGS4 is specifically mediated by dopamine D1 and D2 receptors: clues for RGS2 and RGS4 functions. J Neurochem 2003;84:1118-27. [PubMed: 12603835]

15. Laffargue M, et al. Phosphoinositide 3-kinase gamma is an essential amplifier of mast cell function. Immunity 2002;16:441-51. [PubMed: 11911828]

16. Heximer SP, Watson N, Linder ME, Blumer KJ, Hepler JR. RGS2/G0S8 is a selective inhibitor of Gqalpha function. Proc Natl Acad Sci U S A 1997;94:14389-93. [PubMed: 9405622]

17. Fukao T, Terauchi Y, Kadowaki T, Koyasu S. Role of phosphoinositide 3-kinase signaling in mast cells: new insights from knockout mouse studies. J Mol Med 2003;81:524-35. [PubMed: 12928787]

18. Yu M, Lowell CA, Neel BG, Gu H. Scaffolding adapter Grb2-associated binder 2 requires Syk to transmit signals from FcepsilonRI. J Immunol 2006;176:2421-9. [PubMed: 16456001]

19. Gu H, et al. Essential role for Gab2 in the allergic response. Nature 2001;412:186-90. [PubMed: 11449275] 
20. Xie ZH, Ambudkar I, Siraganian RP. The adapter molecule Gab2 regulates Fc epsilon RI-mediated signal transduction in mast cells. J Immunol 2002;168:4682-91. [PubMed: 11971018]

21. Yamanashi Y, et al. Activation of Src-like protein-tyrosine kinase Lyn and its association with phosphatidylinositol 3-kinase upon B-cell antigen receptor-mediated signaling. Proc Natl Acad Sci U S A 1992;89:1118-22. [PubMed: 1371009]

22. Cuevas BD, et al. Tyrosine phosphorylation of p 85 relieves its inhibitory activity on phosphatidylinositol 3-kinase. J Biol Chem 2001;276:27455-61. [PubMed: 11337495]

23. Zhu M, Rhee I, Liu Y, Zhang W. Negative regulation of Fc epsilonRI-mediated signaling and mast cell function by the adaptor protein LAX. J Biol Chem 2006;281:18408-13. [PubMed: 16672218]

24. Andrade MV, Hiragun T, Beaven MA. Dexamethasone suppresses antigen-induced activation of phosphatidylinositol 3-kinase and downstream responses in mast cells. J Immunol 2004;172:725462. [PubMed: 15187100]

25. Zhang J, Berenstein EH, Evans RL, Siraganian RP. Transfection of Syk protein tyrosine kinase reconstitutes high affinity $\mathrm{IgE}$ receptor-mediated degranulation in a Syk-negative variant of rat basophilic leukemia RBL-2H3 cells. J Exp Med 1996;184:71-9. [PubMed: 8691151]

26. Reischl IG, Coward WR, Church MK. Molecular consequences of human mast cell activation following immunoglobulin E-high-affinity immunoglobulin E receptor (IgE-FcepsilonRI) interaction. Biochem Pharmacol 1999;58:1841-50. [PubMed: 10591138]

27. Vanhaesebroeck B, Ali K, Bilancio A, Geering B, Foukas LC. Signalling by PI3K isoforms: insights from gene-targeted mice. Trends Biochem Sci 2005;30:194-204. [PubMed: 15817396]

28. Nechushtan H, Leitges M, Cohen C, Kay G, Razin E. Inhibition of degranulation and interleukin-6 production in mast cells derived from mice deficient in protein kinase Cbeta. Blood 2000;95:17527. [PubMed: 10688834]

29. Leitges $\mathrm{M}$, et al. Protein kinase C-delta is a negative regulator of antigen-induced mast cell degranulation. Mol Cell Biol 2002;22:3970-80. [PubMed: 12024011]

30. Zhang C, Hirasawa N, Beaven MA. Antigen activation of mitogen-activated protein kinase in mast cells through protein kinase C-dependent and independent pathways. J Immunol 1997;158:4968-75. [PubMed: 9144516]

31. Olenchock BA, et al. Impaired degranulation but enhanced cytokine production after Fc epsilonRI stimulation of diacylglycerol kinase zeta-deficient mast cells. J Exp Med 2006;203:1471-80. [PubMed: 16717114]

32. Kitaura J, et al. Akt-dependent cytokine production in mast cells. J Exp Med 2000;192:729-40. [PubMed: 10974038]

33. Dong B, Valencia CA, Liu R. Ca2+/calmodulin directly interacts with the PH domain of AKT1. J Biol Chem. 2007

34. Popov SG, Krishna UM, Falck JR, Wilkie TM. Ca2+/Calmodulin reverses phosphatidylinositol 3,4, 5-trisphosphate-dependent inhibition of regulators of G protein-signaling GTPase-activating protein activity. J Biol Chem 2000;275:18962-8. [PubMed: 10747990]

35. Hollinger S, Hepler JR. Cellular regulation of RGS proteins: modulators and integrators of G protein signaling. Pharmacol Rev 2002;54:527-59. [PubMed: 12223533]

36. Lu-Kuo JM, Fruman DA, Joyal DM, Cantley LC, Katz HR. Impaired kit- but not FcepsilonRI-initiated mast cell activation in the absence of phosphoinositide 3-kinase p85alpha gene products. J Biol Chem 2000;275:6022-9. [PubMed: 10681597]

37. Bernstein LS, Grillo AA, Loranger SS, Linder ME. RGS4 binds to membranes through an amphipathic alpha -helix. J Biol Chem 2000;275:18520-6. [PubMed: 10764749]

38. Tesmer JJ, Berman DM, Gilman AG, Sprang SR. Structure of RGS4 bound to AlF4--activated G(i alpha1): stabilization of the transition state for GTP hydrolysis. Cell 1997;89:251-61. [PubMed: 9108480]

39. Heximer SP, Blumer KJ. RGS proteins: Swiss army knives in seven-transmembrane domain receptor signaling networks. Sci STKE 2007 2007:pe2.

40. Wang X, et al. Spinophilin regulates $\mathrm{Ca} 2+$ signalling by binding the $\mathrm{N}$-terminal domain of RGS2 and the third intracellular loop of G-protein-coupled receptors. Nat Cell Biol 2005;7:405-11. [PubMed: 15793568] 
41. Liu W, et al. Adrenergic modulation of NMDA receptors in prefrontal cortex is differentially regulated by RGS proteins and spinophilin. Proc Natl Acad Sci U S A 2006;103:18338-43. [PubMed: 17101972]

42. Hague C, et al. Selective inhibition of alpha1A-adrenergic receptor signaling by RGS2 association with the receptor third intracellular loop. J Biol Chem 2005;280:27289-95. [PubMed: 15917235]

43. Han SB, et al. Rgs1 and Gnai2 regulate the entrance of B lymphocytes into lymph nodes and B cell motility within lymph node follicles. Immunity 2005;22:343-54. [PubMed: 15780991]

44. Shi GX, Harrison K, Wilson GL, Moratz C, Kehrl JH. RGS13 regulates germinal center B lymphocytes responsiveness to CXC chemokine ligand (CXCL) 12 and CXCL13. J Immunol 2002;169:2507-15. [PubMed: 12193720]

45. Estes JD, et al. Follicular dendritic cell regulation of CXCR4-mediated germinal center CD4 T cell migration. J Immunol 2004;173:6169-78. [PubMed: 15528354]

46. Beadling C, Druey KM, Richter G, Kehrl JH, Smith KA. Regulators of G protein signaling exhibit distinct patterns of gene expression and target $\mathrm{G}$ protein specificity in human lymphocytes. J Immunol 1999;162:2677-82. [PubMed: 10072511]

47. Youssef LA, et al. Histamine Release from the Basophils of Control and Asthmatic Subjects and a Comparison of Gene Expression between "Releaser" and "Nonreleaser" Basophils. J Immunol 2007;178:4584-94. [PubMed: 17372017]

48. Saitoh $\mathrm{S}$, et al. LAT is essential for Fc(epsilon)RI-mediated mast cell activation. Immunity 2000;12:525-35. [PubMed: 10843385]

49. Dombrowicz D, Flamand V, Brigman KK, Koller BH, Kinet JP. Abolition of anaphylaxis by targeted disruption of the high affinity immunoglobulin E receptor alpha chain gene. Cell 1993;75:969-76. [PubMed: 8252632]

50. Manetz TS, et al. Vav1 regulates phospholipase cgamma activation and calcium responses in mast cells. Mol Cell Biol 2001;21:3763-74. [PubMed: 11340169]

51. Nagahara H, et al. Transduction of full-length TAT fusion proteins into mammalian cells: TATp27Kip1 induces cell migration. Nat Med 1998;4:1449-52. [PubMed: 9846587] 
a

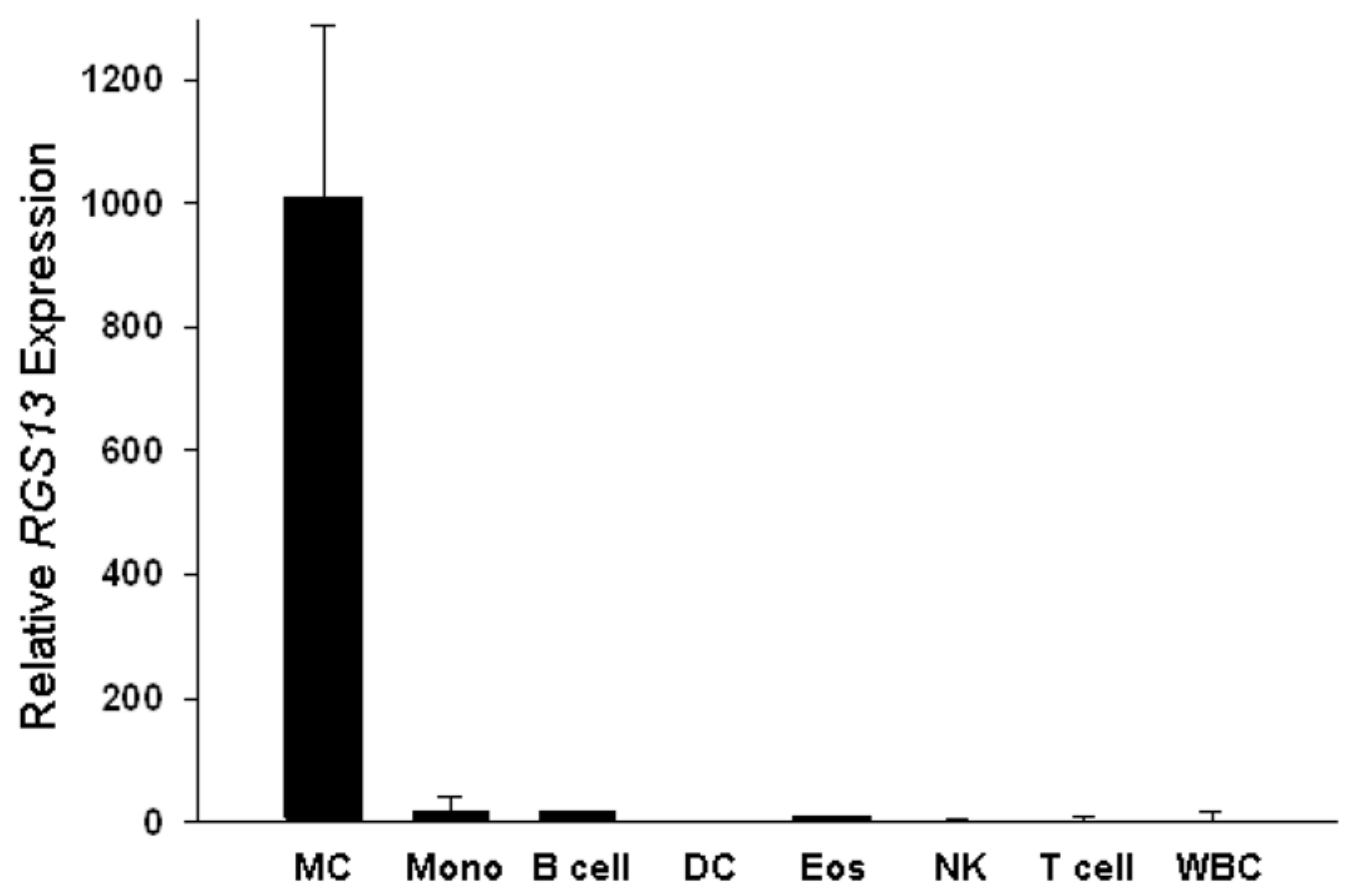


b

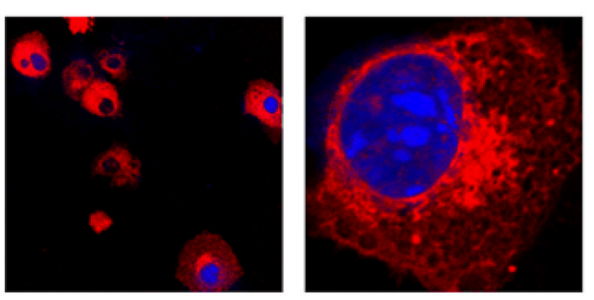

Rgs13

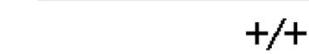

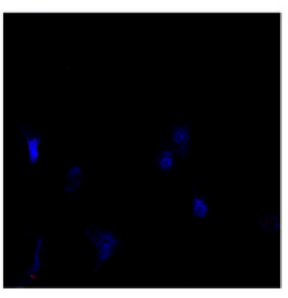

$-/-$

C

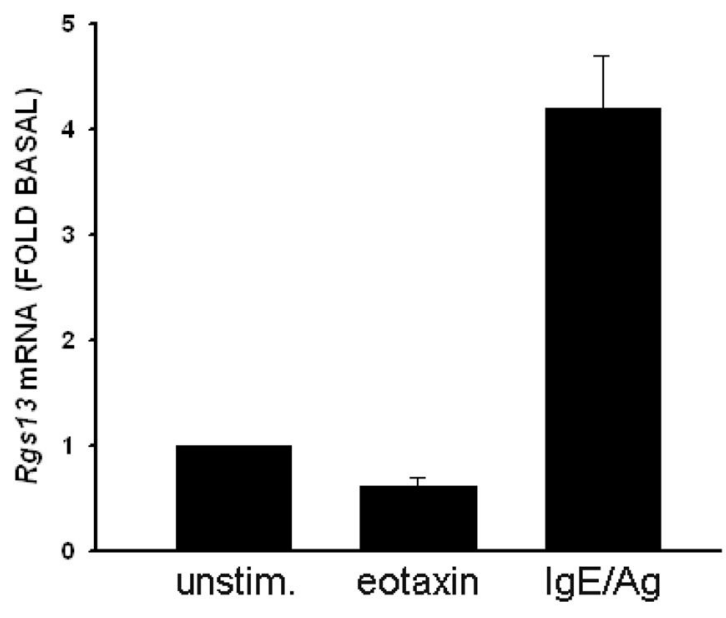

d

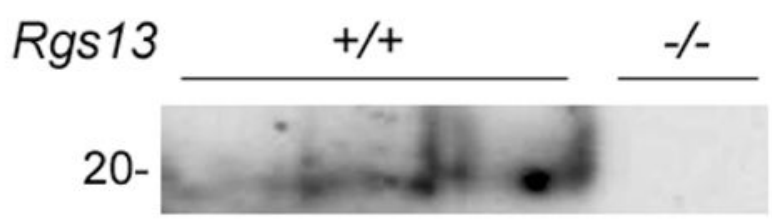

WB:

RGS13

45-

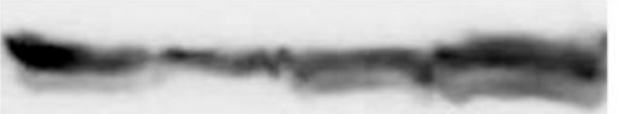

$\beta$-actin

$\begin{array}{llllll}\text { Ag } & 0 & 4 & 24 & 24 & \text { (hr.) }\end{array}$

Figure 1. Enriched expression of Rgs13 in mast cells

(a) Analysis of RGS13 expression in human hematopoietic cells by microarray. Mature MCs and eosinophils (Eos) were derived from peripheral blood progenitors as described in the Methods. RNA was hybridized to Affymetrix ${ }^{\circledR}$ gene chips and compared to expression values for the other indicated hematopoietic cell subsets obtained from the Gene Logic 
Bioexpressтм database. Values represent mean $+/-$ S.D. of 1-4 donor sources. DC=dendritic cells; Mono=monocytes; $\mathrm{NK}=$ natural killer cells; $\mathrm{WBC}=$ unfractionated white blood cells; Eos=eosinophils. (b) Cytosolic expression of Rgs13 in BMMCs. 4-week old BMMCs from WT or Rgs 13-I- mice were plated on glass coverslips by cytospin and immunostained with polyclonal anti-RGS13 antibody followed by Texas Red-conjugated anti rabbit IgG and DAPI to identify nuclei. (c) qPCR analysis of Rgsl3 mRNA expression. BMMCs were left unstimulated or treated with eotaxin $\left(50 \mathrm{ng} \mathrm{ml}^{-1}\right)$ or IgE/DNP for $24 \mathrm{hrs}$. prior to RNA isolation. Rgs 13 mRNA was quantitated by real-time qPCR as detailed in the Methods. (d) BMMCs were sensitized with IgE and left untreated or challenged with Ag for 4 or 24 hrs. before cell lysis and evaluation of Rgs13 levels by immunoblotting. 
a

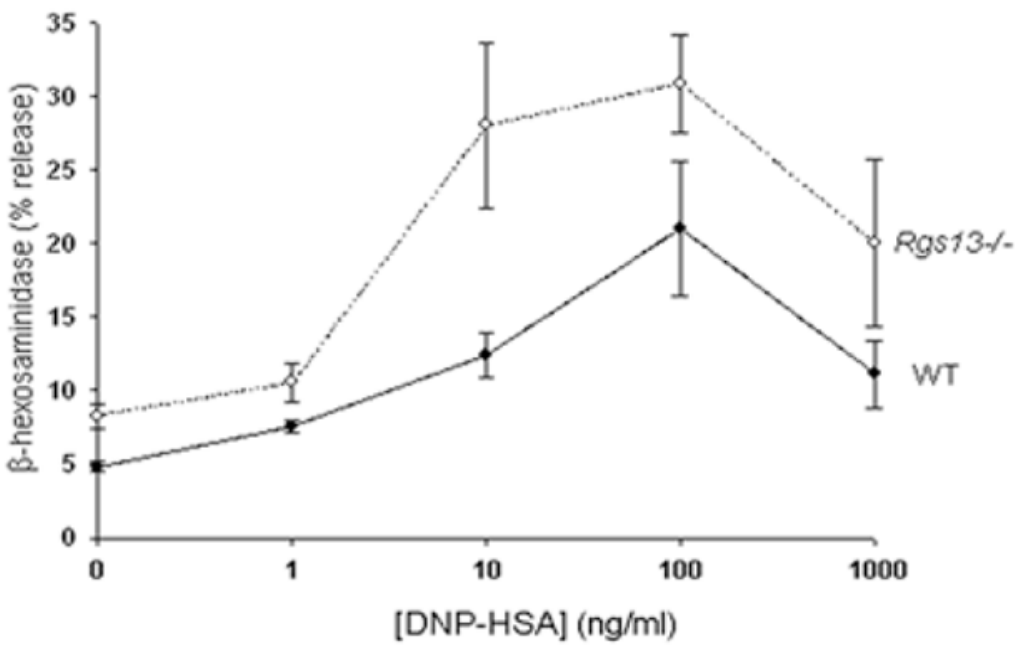


b

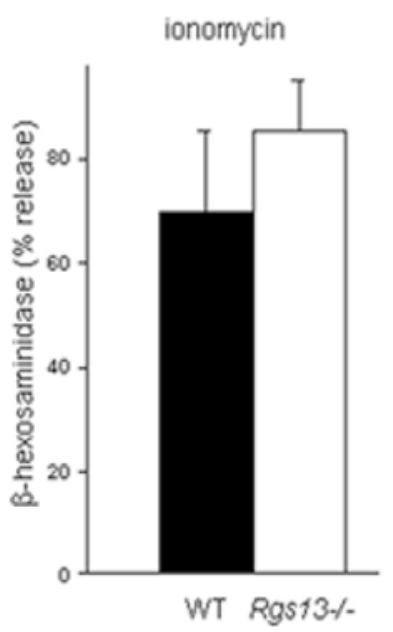

C

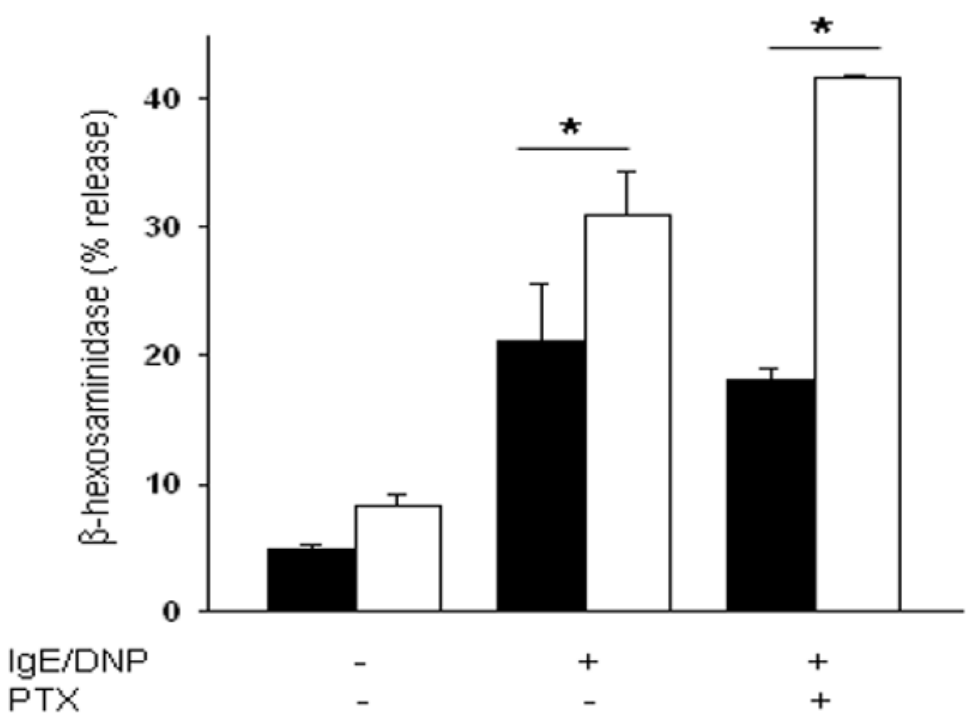



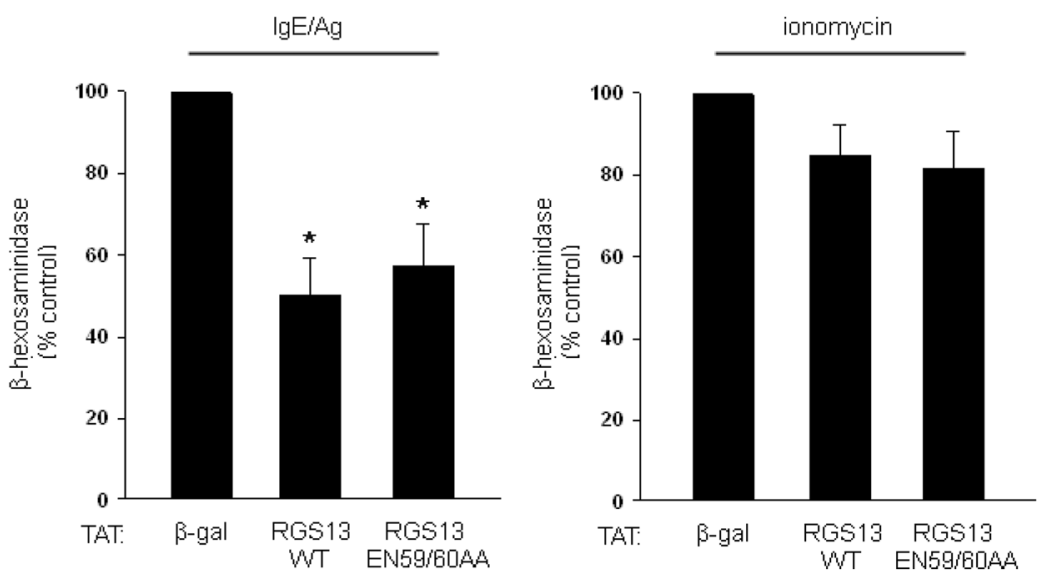

Figure 2. Rgs13 inhibits IgE-dependent MC degranulation independent of GAP activity

(a), Enhanced Ag-evoked degranulation by Rgs13-/- BMMCs. WT (solid line) or Rgs 13-/cells (dashed line) were stimulated with indicated DNP-HSA concentrations for $30 \mathrm{~min}$. prior to measurement of $\beta$-hexosaminidase release (mean $+/-$ S.E.M. of at least 4 experiments expressed as percent of total $\beta$-hexosaminidase content; for DNP, $\mathrm{p}=0.001$, two way analysis of variance [ANOVA]). (b) Ionomycin induced degranulation is similar in WT (black bar) and Rgs 13-/- (white bar) BMMCs. Cells were stimulated for $30 \mathrm{~min}$. with ionomycin $(5 \mu \mathrm{M})$ and degranulation measured as in (a). (c) Same experiment as (a) except cells were pre-incubated in the presence or absence of PTX $\left(100 \mathrm{ng} \mathrm{ml}^{-1}\right)$ for 2 hrs. prior to Ag stimulation ( $\mathrm{n}=4$ experiments; *p=0.001, 2 way-ANOVA). (d) Reconstitution of Rgs 13-/- BMMCs with WT and GAP-inactive RGS13. TAT- $\beta$-galactosidase, TAT RGS13(WT), or TAT-RGS13

(EN59/60AA) (100 nM) was added to IgE-sensitized Rgs13-/- BMMCs 30 min. prior to Ag stimulation, and $\beta$-hexosaminidase release was measured as in (c). Values represent mean + / - S.E.M. $(n=3)$ of percentage of TAT- $\beta$-gal control value; $* \mathrm{p}<0.05$, one way ANOVA. Basal release ( $2.5 \%$ total $\beta$-hexosaminidase content) did not vary significantly among the conditions. 
a

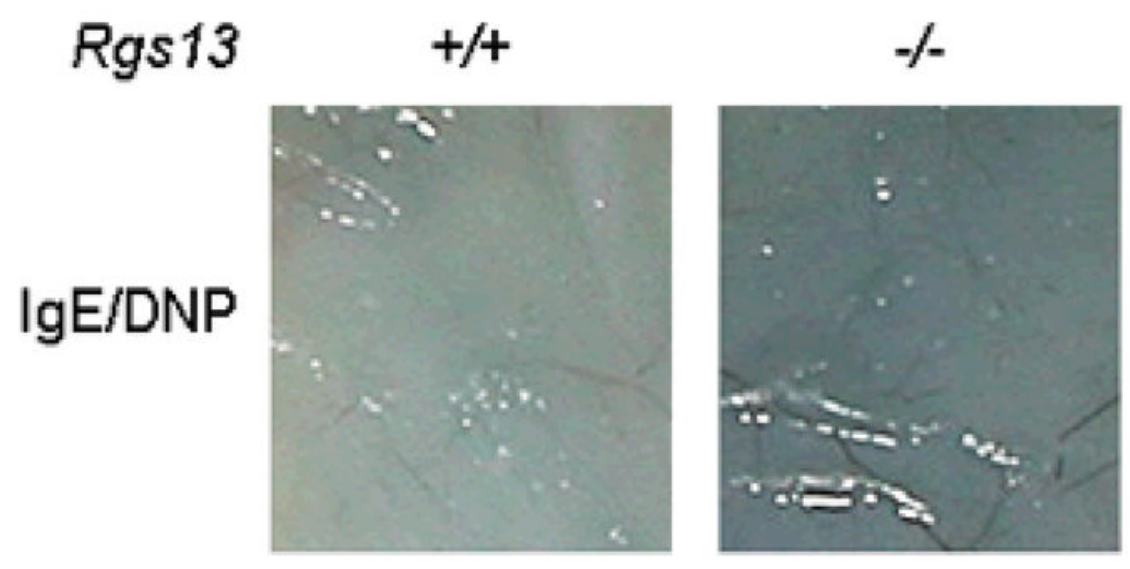

NS/DNP
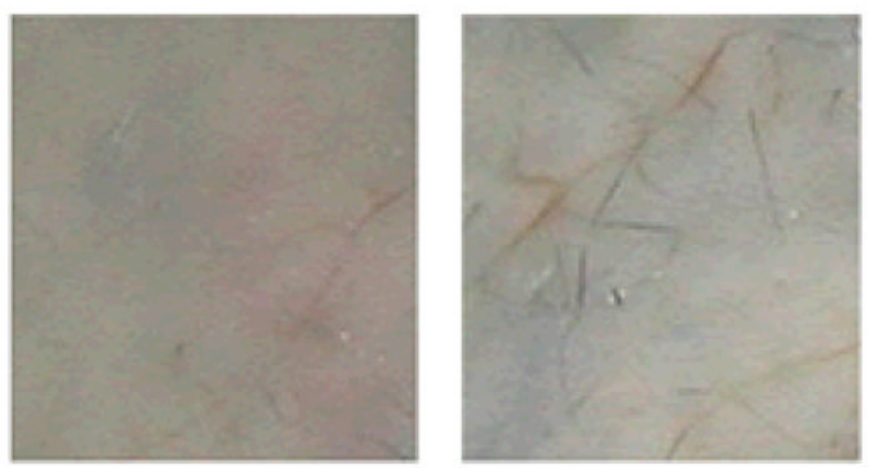
b

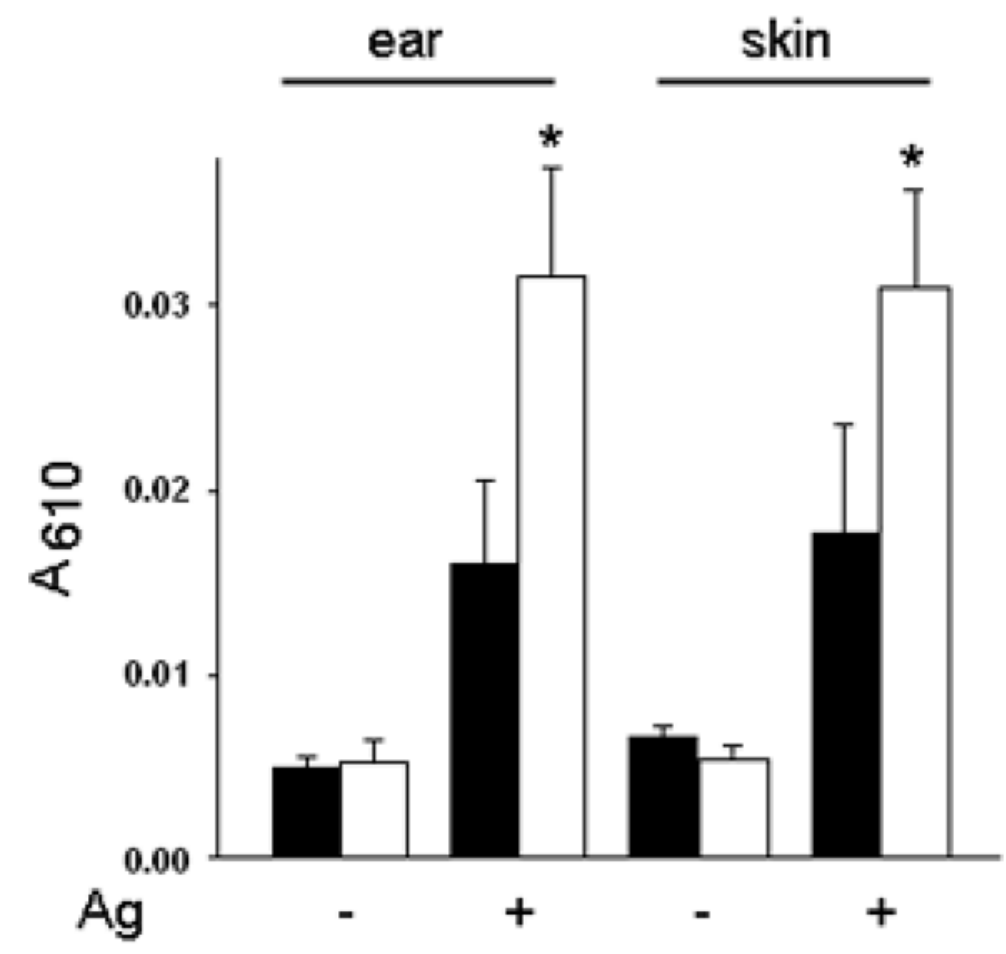

Figure 3. Enhanced passive cutaneous anaphylaxis in Rgs $13-/-$ mice

(a) Mice were sensitized with anti-DNP IgE (75 ng) or normal saline (NS) intradermally followed by next day challenge with DNP-HSA $(100 \mu \mathrm{g})$ intravenously in saline containing $0.5 \%$ Evans blue. After $30 \mathrm{~min}$., mice were sacrificed and the back skin was exposed. (b) Evans blue from the reaction site was extracted in formaldehyde and quantitated by spectrophotometry at $610 \mathrm{~nm}$ [bar graph (black bars $=$ WT, white bars $=R g s 13-/-$ ) represents mean values \pm S.E.M. $(n=3) ;(* \mathrm{p}<0.05$ paired $t$ test $)$. 
a

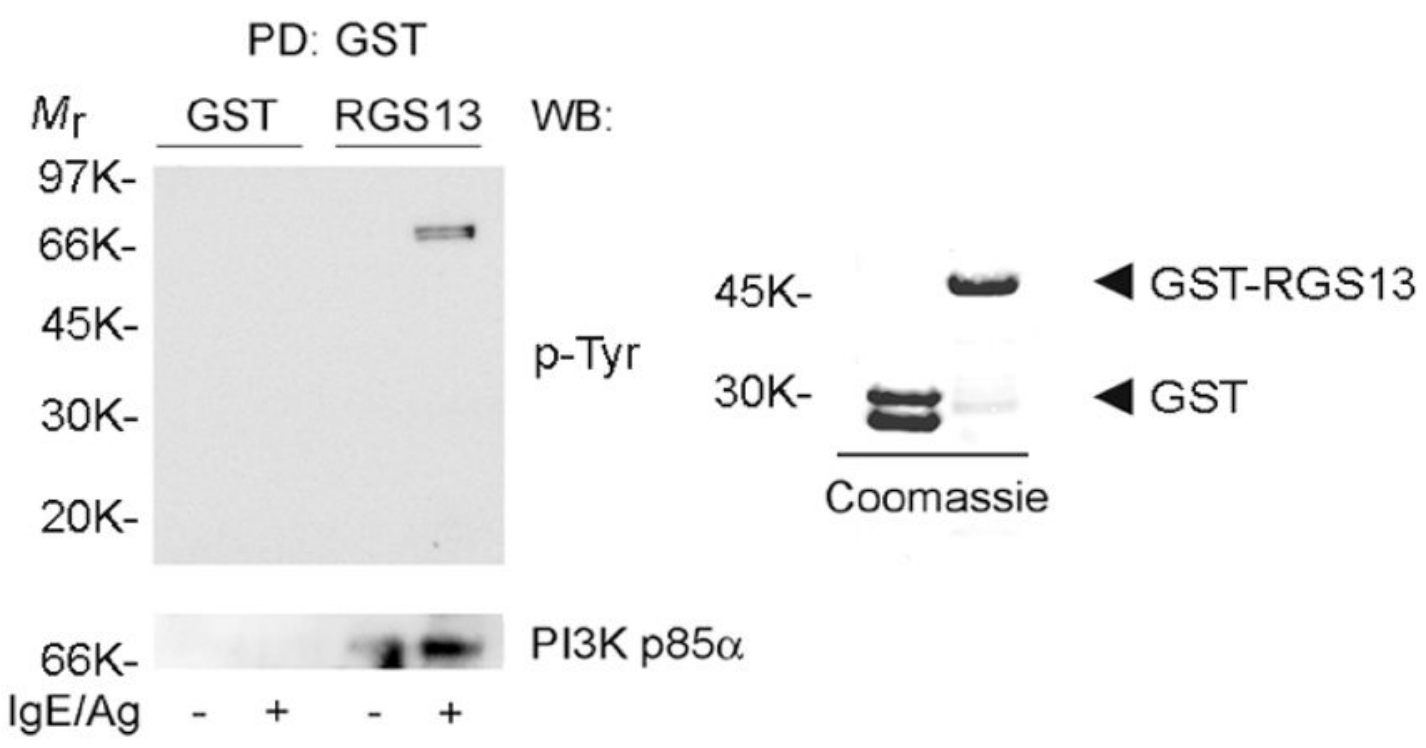

Nat Immunol. Author manuscript; available in PMC 2008 May 20. 
b

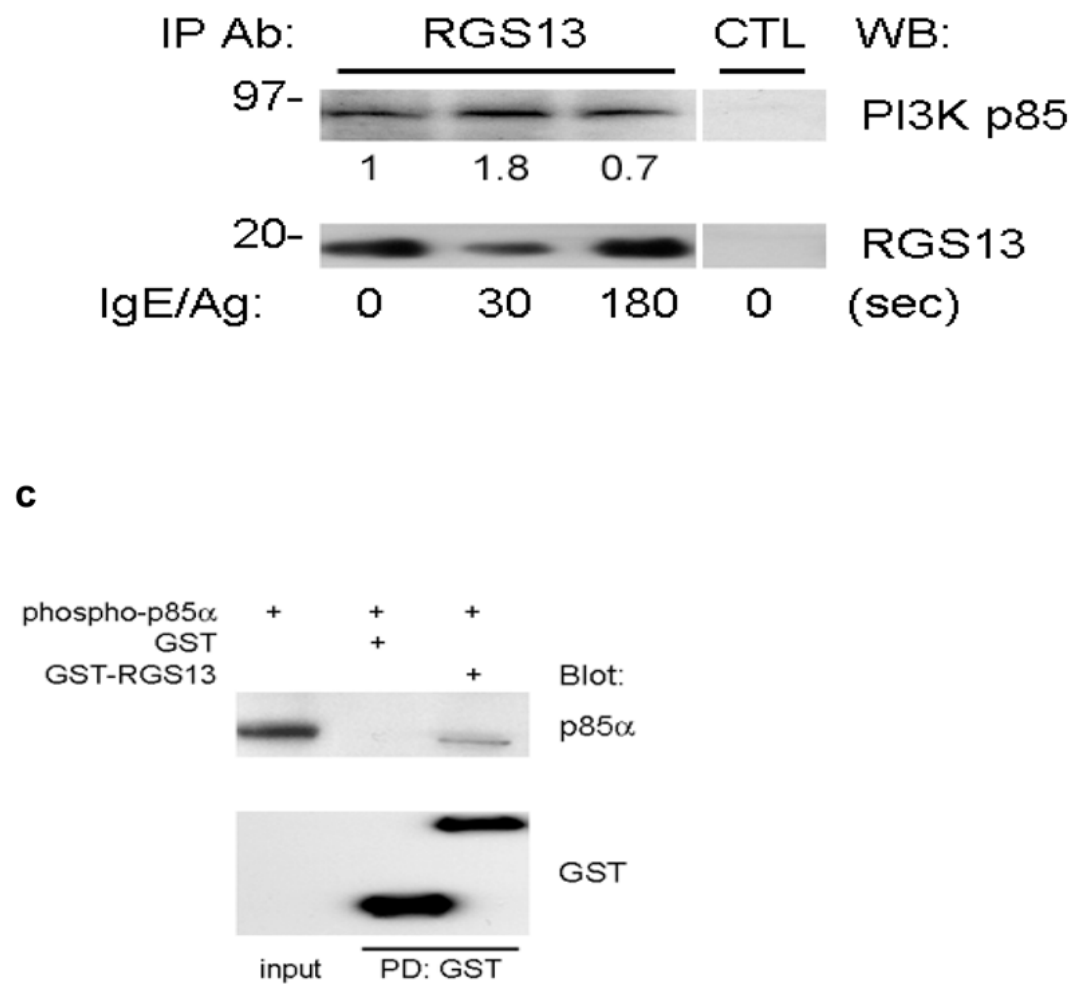

d
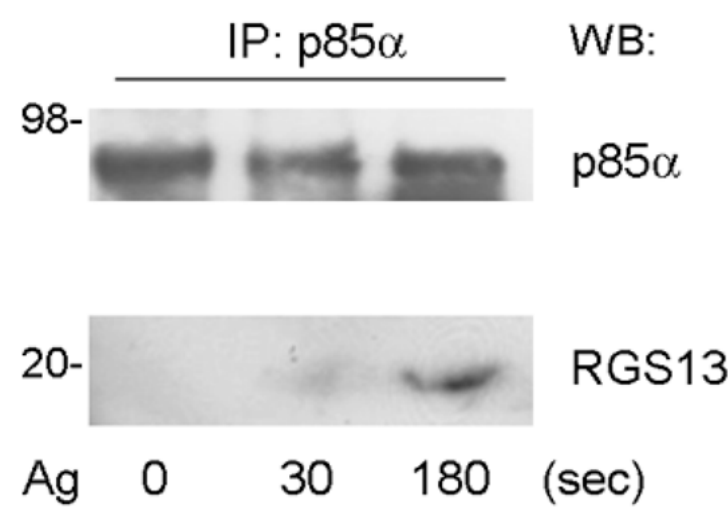

Figure 4. Rgs13 interacts with the regulatory p85 $\alpha$ PI(3)K subunit

(a) Bead-immobilized GST or GST-RGS13 was incubated with BMMC lysates and washed followed by sequential immunoblotting with anti-pTyr and anti-p85 $\alpha$ (left panel). The integrity of recombinant GST and GST-RGS13 was verified by Coomassie blue staining (right panel). (b) RBL-2H3 cells were stimulated with Ag for the indicated times followed by immunoprecipitation of cell lysates with rabbit IgG (CTL) or rabbit anti-RGS13 and immunoblotting with anti-p85 $\alpha$ and anti-RGS13. The relative amounts of $\mathrm{p} 85 \alpha$ normalized by the amount of Rgs13 in each immunoprecipitate were quantitated by densitometry. (c) Recombinant $\mathrm{p} 85 \alpha$ was pre-incubated with Lyn tyrosine kinase followed by exposure to either GST or GST-RGS13 coupled to glutathione sepharose. Binding reactions were washed 
extensively and immunoblotted as indicated. (d) Endogenous p85 $\alpha$ was immunoprecipitated from cell lysates of BMMCs either untreated or stimulated with Ag for the indicated time periods followed by immunoblotting with the indicated antibodies. 
a

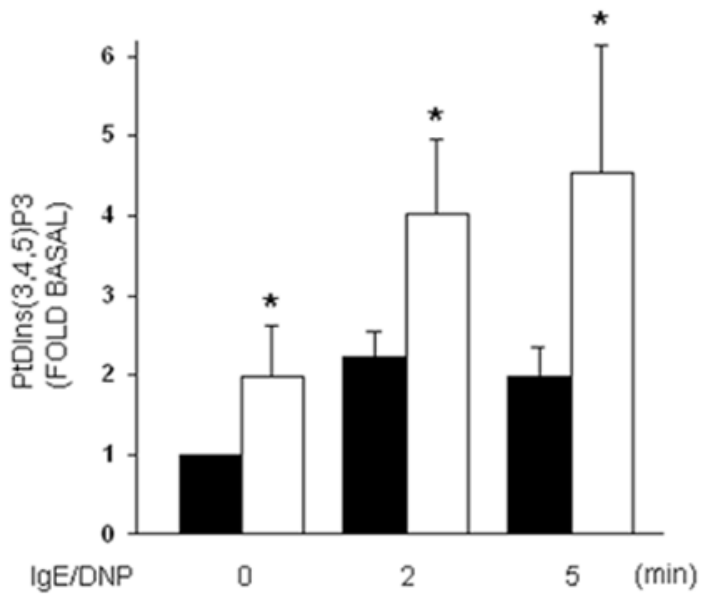

b

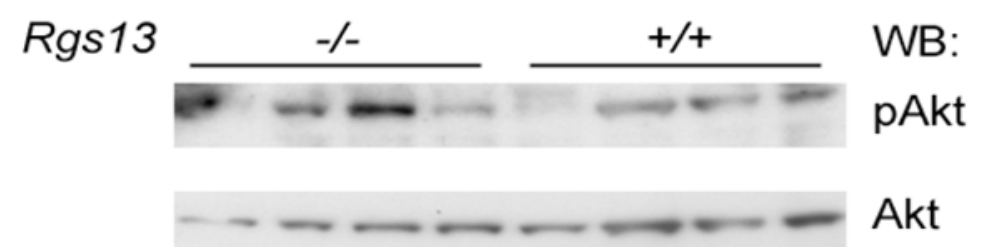

$\begin{array}{llllllllll}\mathrm{Ag} & 0 & 2 & 10 & 30 & 0 & 2 & 10 & 30 & \text { (min) }\end{array}$ 
C

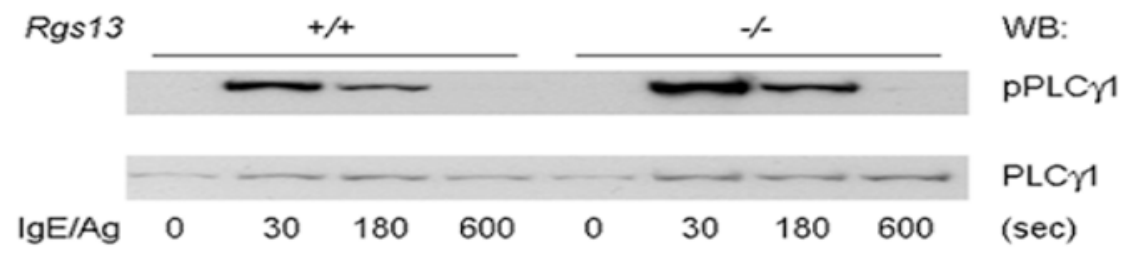

d
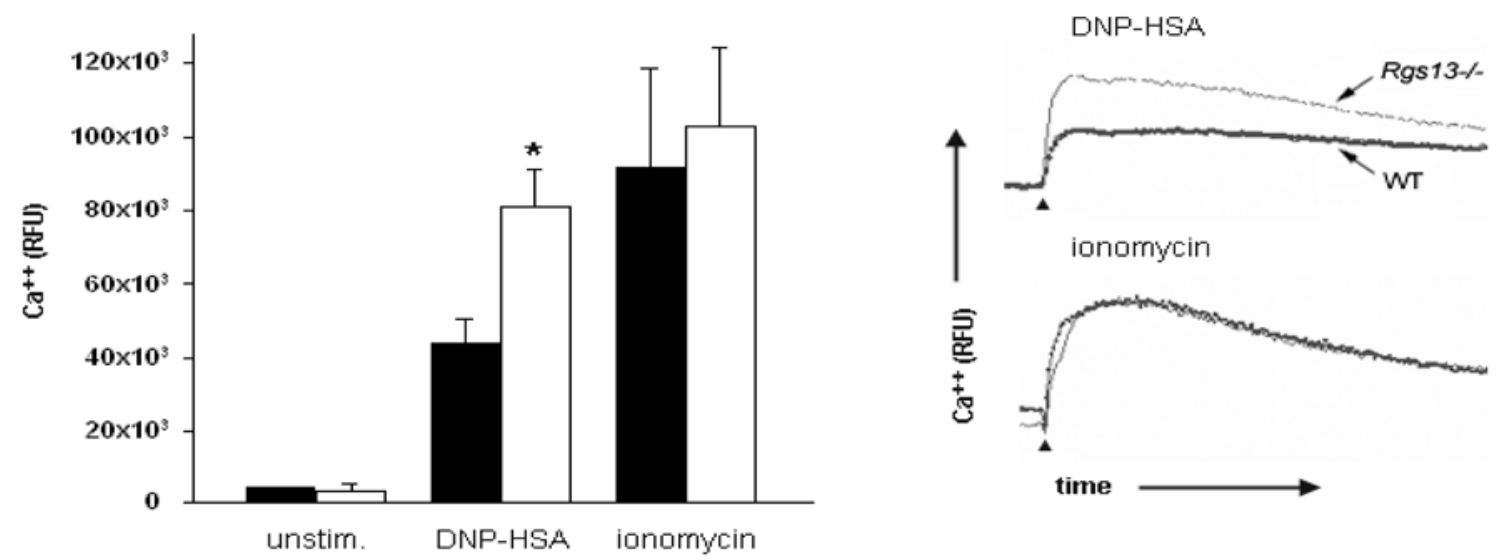

Figure 5. Increased Ag-evoked PI(3)K activity and downstream signaling events in Rgs13-/- MCs (a) Increased Ag-evoked PtdIns(3,4,5)P3 formation in the absence of Rgs13. Sensitized WT (black bars) or Rgs13-/- (white bars) BMMCs were stimulated with DNP-HSA for the indicated times followed by phospholipid extraction and separation by thin layer chromatography. Values are mean +/- S.E.M. from 3 independent experiments of the foldincrease of PtdIns(3,4,5)P3 levels over unstimulated cells measured by densitometry (*p=0.016, 2-way ANOVA). (b) Increased Ag-induced Akt phosphorylation in Rgs13-/BMMCs. Sensitized cells were stimulated with Ag for the indicated times followed by detergent lysis and sequential immunoblotting with anti-phosphoAkt(Thr308) and anti-Akt. (c) PLC $\gamma 1$ phosphorylation in Ag-challenged MCs. Same experiment as (b) except blots were probed with anti-phosphoPLC $\gamma 1$ and anti-PLC $\gamma 1$. (d) $\mathrm{Ca}^{++}$flux in BMMCs was measured by fluorimetry after stimulation as indicated. WT (black bars) and Rgs 13-/- (white bars) values are mean \pm S.E.M. of 3 independent experiments ( $* \mathrm{p}=0.01,2$ way ANOVA). Representative kinetic traces of intracellular $\mathrm{Ca}^{++}$concentration are shown on the right. Time of stimulus addition is indicated by arrowheads. 
a
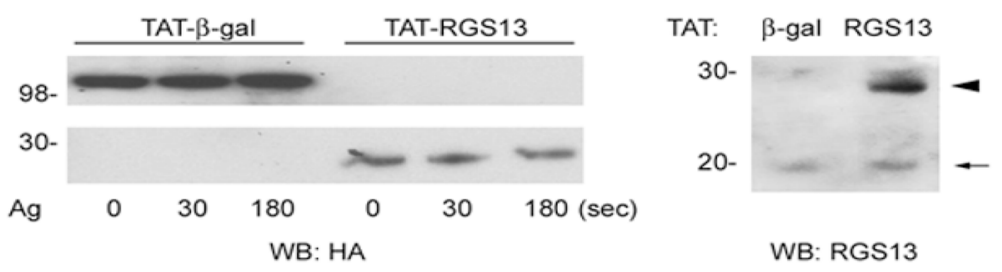

b

TAT- $\beta$-gal

$\square$ TAT-RGS13

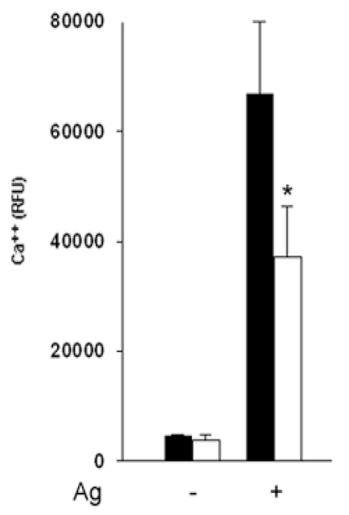

C
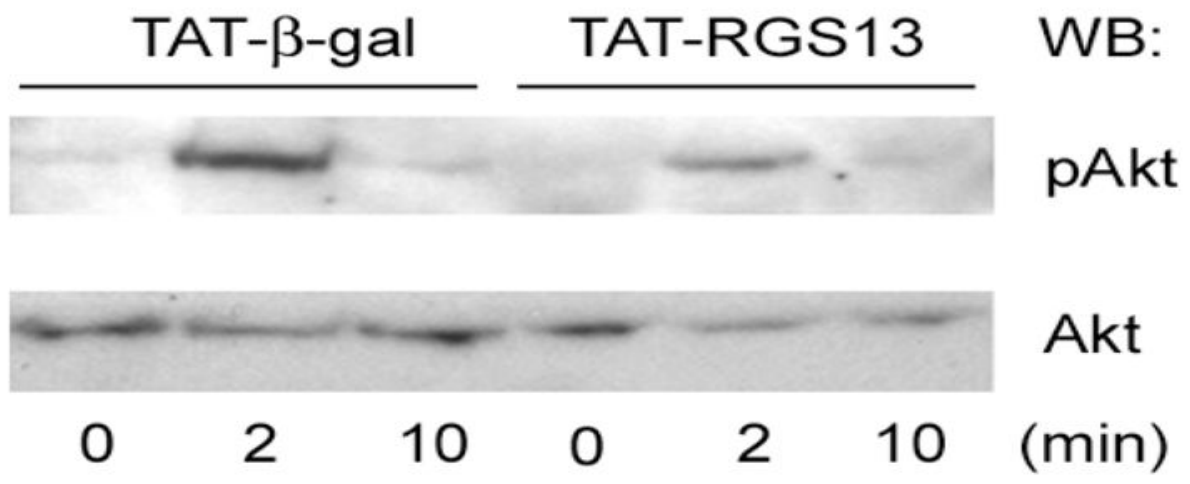
Ag
10
$210(\min )$

Figure 6. RGS13 expression in WT BMMCs inhibits Ag-induced $\mathrm{Ca}^{++}$flux and Akt activation TAT- $\beta$-galactosidase or TAT-RGS13 was transduced into WT BMMCs prior to Ag stimulation. (a) Expression of TAT fusion proteins was detected with anti-HA antibody (left panel). RGS13 levels in cells transduced with TAT- $\beta$-galactosidase were compared to cells transduced with TAT-RGS13 (arrowhead) by immunoblotting with an RGS13-specific antibody. Endogenous Rgs13 levels ( $20 \mathrm{kDa}$ band, arrow) were similar in both cells. (b) Cytosolic $\mathrm{Ca}^{++}$mobilization or (c) Akt phosphorylation induced by Ag was analyzed after TAT protein transduction of WT BMMCs. Data represent 3 independent experiments, and in (b) values are the mean $+/-$ S.E.M. for cells transduced with either TAT- $\beta$-galactosidase (black bars) or TAT-RGS13 (white bars) [*p=0.006, 2 way ANOVA]. 
a

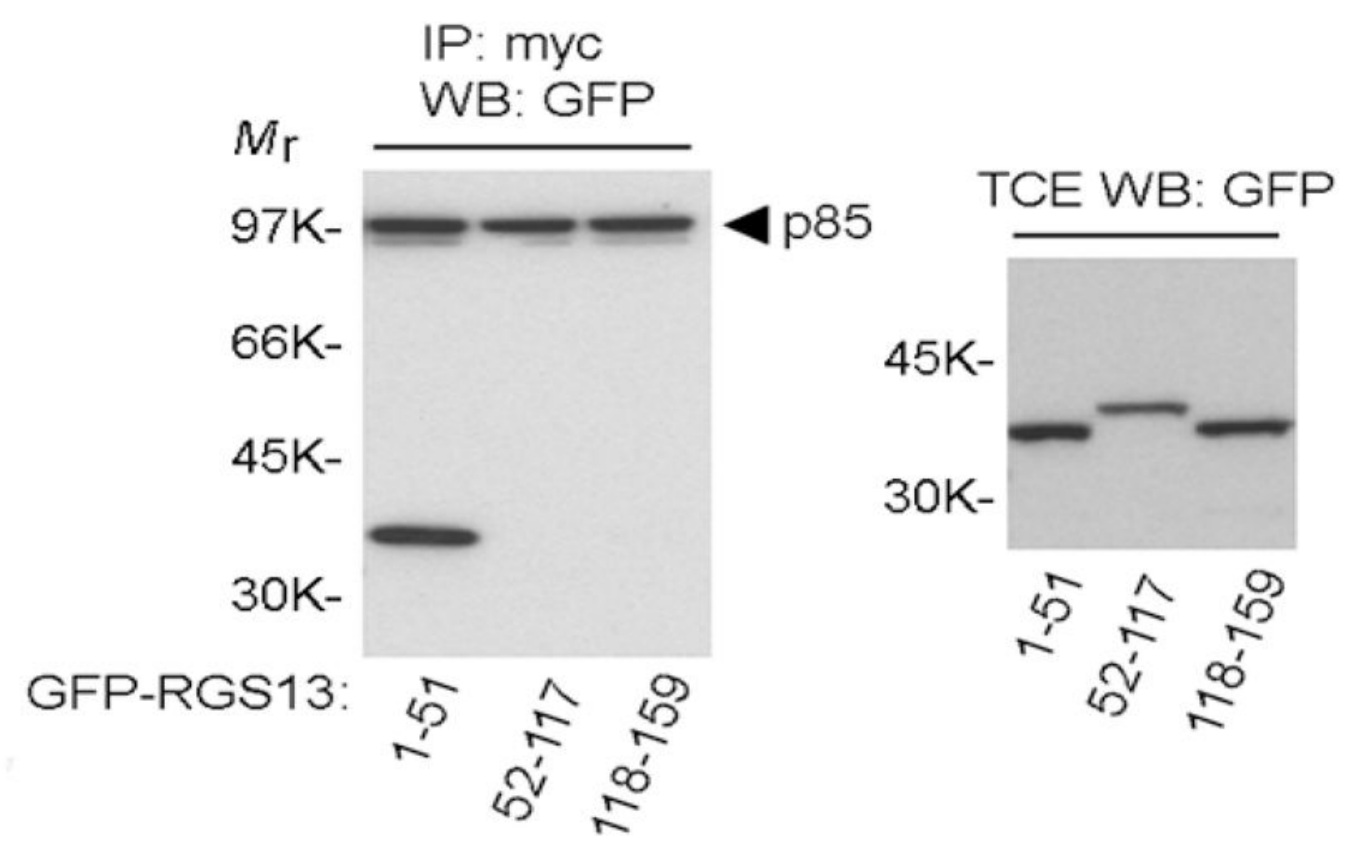

Nat Immunol. Author manuscript; available in PMC 2008 May 20. 
b

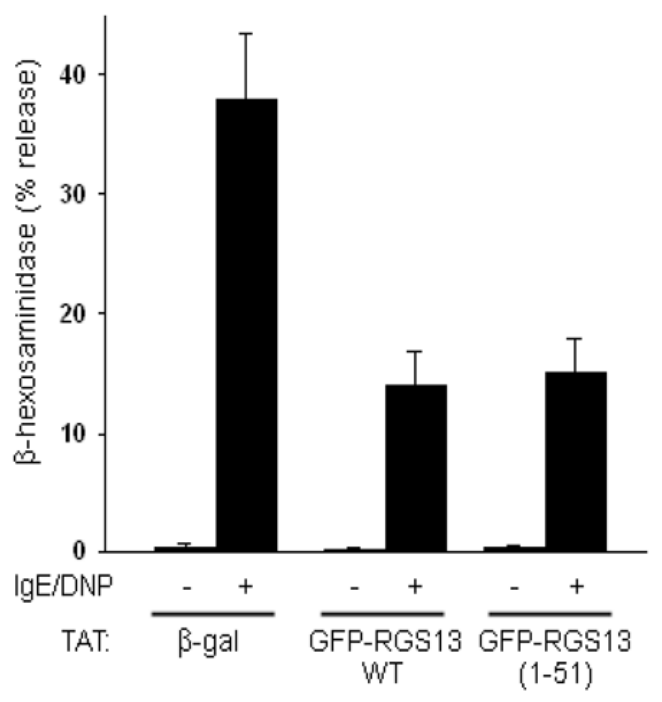

C

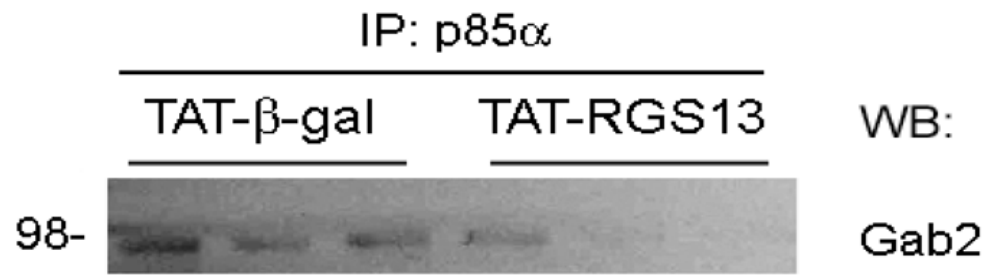

66-

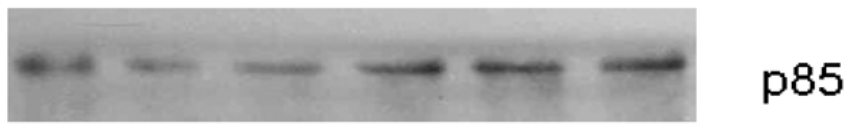

$\begin{array}{llllllll}\mathrm{Ag} & 0 & 30 & 180 & 0 & 30 & 180 & (\mathrm{sec})\end{array}$ 


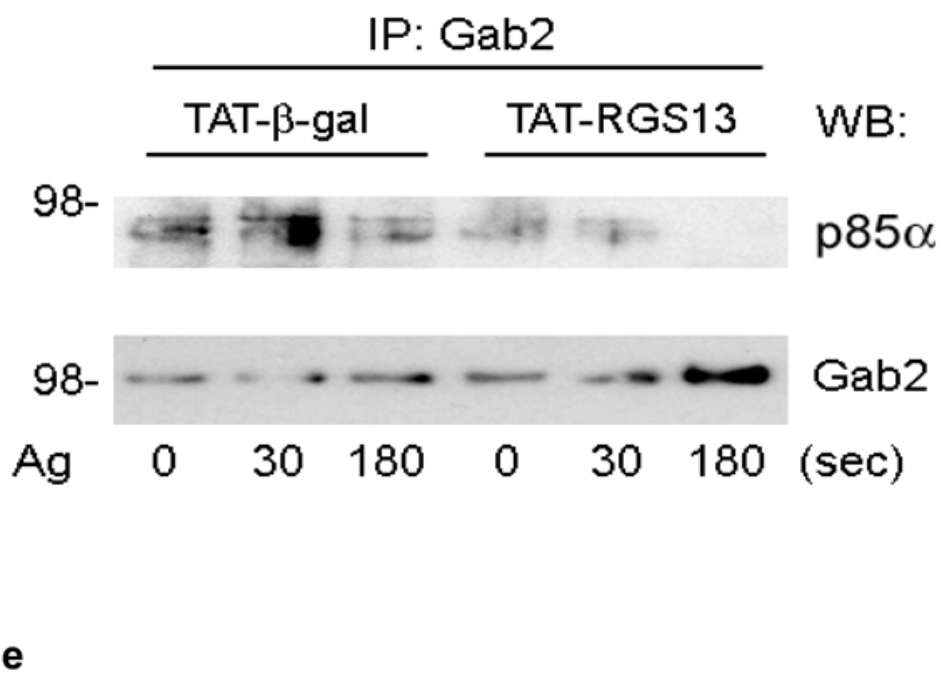

\section{PD: GST-Grb2}

WB:

$\mathrm{p} 85 \alpha$

p1108

Gab2

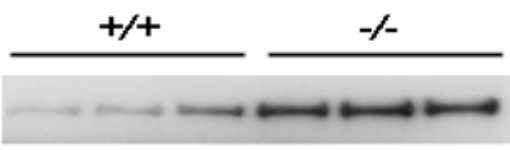

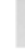
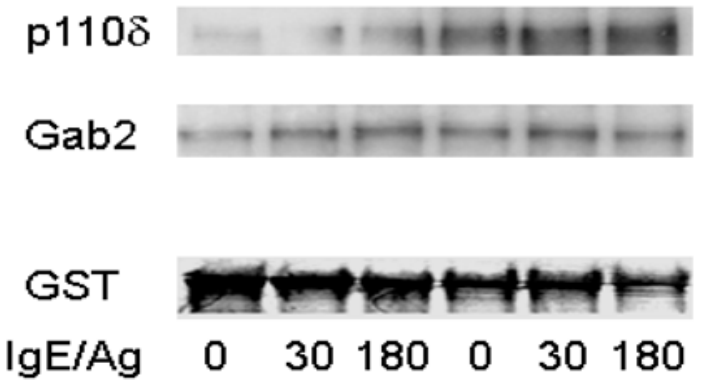

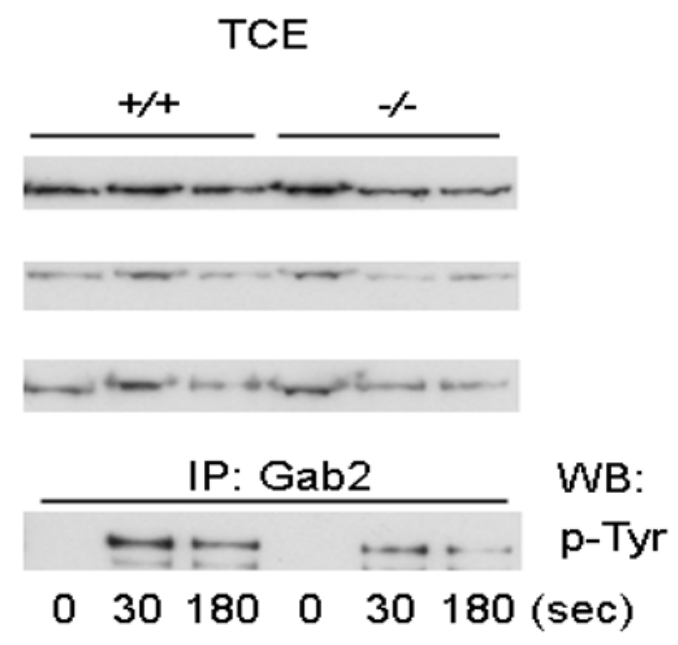

TCE

Figure 7. Mechanism of Rgs13 inhibition of Ag-induced PI(3)K activity in MCs (a) $293 \mathrm{~T}$ cells were transfected with GFP-RGS13 truncation mutants along with mycGFPp85a. Cells were immunoprecipitated with anti-myc followed by immunoblotting with antiGFP. Relative protein expression in total cell extracts (TCE) is shown in right panels. (b) Inhibition of Ag-induced degranulation by an RGS13 amino-terminal polypeptide. Rgs 13-/BMMCs were reconstituted with TAT fusion proteins as indicated followed by measurement of $\beta$-hexosaminidase release as in Fig. 2. Values shown are the mean $+/-$ S.E.M. of percent $\beta$-hexosaminidase release compared to control (TAT- $\beta$-gal) from three independent experiments $(* \mathrm{p}=0.007$, one way ANOVA). Neither of the TAT-RGS13 proteins significantly inhibited degranulation induced by ionomycin (not shown). TAT-RGS13 transduction of WT BMMCs is associated with reduction in Ag-evoked association of p85 and Gab2 as determined by immunoprecipitation with either anti-p85 (c) or anti-Gab2 (d). (e) Lysates from BMMCs sensitized and challenged with Ag for the indicated times were incubated with GST-Grb2 
immobilized on glutathione beads. After washing, pulldowns were immunoblotted with anti$\mathrm{p} 85 \alpha$ and $-\mathrm{p} 110 \delta$. The amount of Gab2 present in pulldowns and expression and phosphorylation in total cell extracts (TCE) were evaluated both by immunoblotting and immunoprecipitation as indicated. Expression of p $85 \alpha$ and p110 in TCE is also shown. 

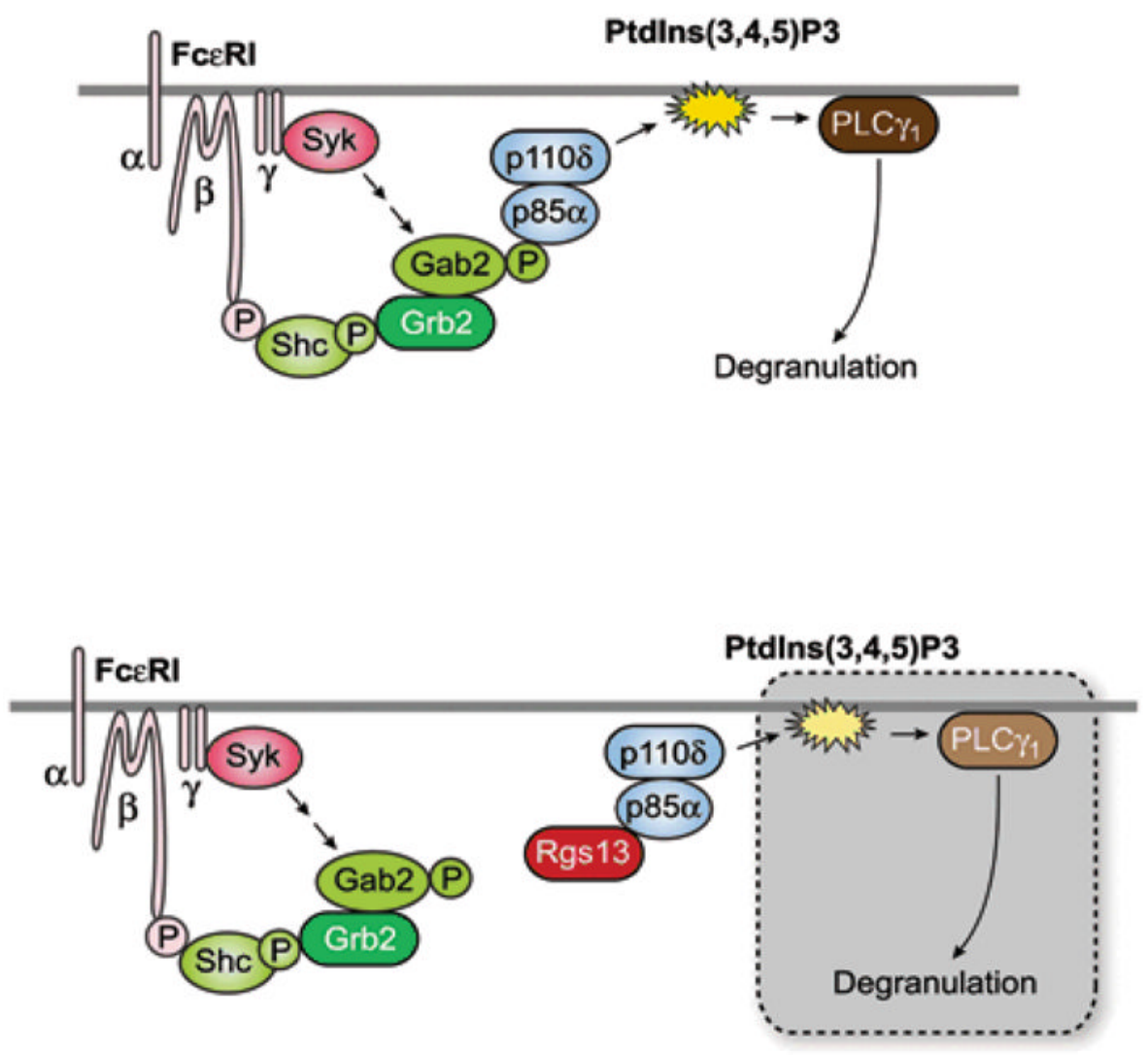

Figure 8. A model for the regulation of FceRI-mediated MC degranulation by Rgs13

Ag stimulation induces assembly of a scaffold that may include Shc, Grb2, and phosphoGab2 at FceRI. PI(3)K is recruited to the complex through its p85 regulatory subunit, which binds phosphorylated Gab2 and positions the catalytic p110 $\delta$ subunit in proximity to phospholipid substrates. PI(3)K-mediated conversion of PtdIns(4,5)P2 to PtdIns(3,4,5)P3 results in activation of downstream enzymes such as PLC $\gamma 1$ necessary for degranulation (upper panel). Rgs13 may limit the amount of p85bound to the Gab2-containing scaffold, resulting in decreased PI(3)K and PLC $\gamma 1$ activity and reduced degranulation (lower panel). 


\section{Table 1}

Mast cell tissue distribution in WT and Rgs 13-/- mice

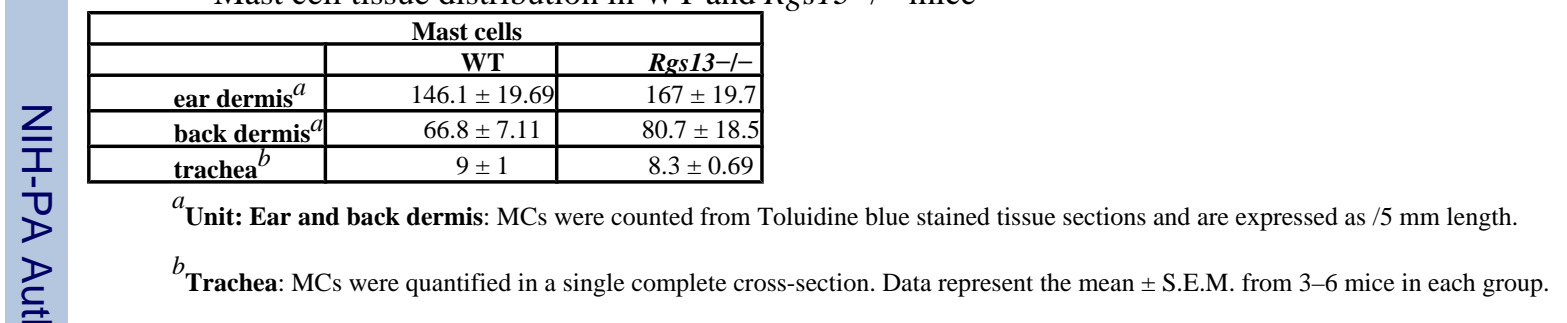

